\title{
EKONOMIHÖGSKOLAN
}

Lunds universitet

\section{Supra-National Origin Marking Schemes}

-A situated consumer perspective of the working meanings and potential viability of stretching origin-with reference to the European Union-

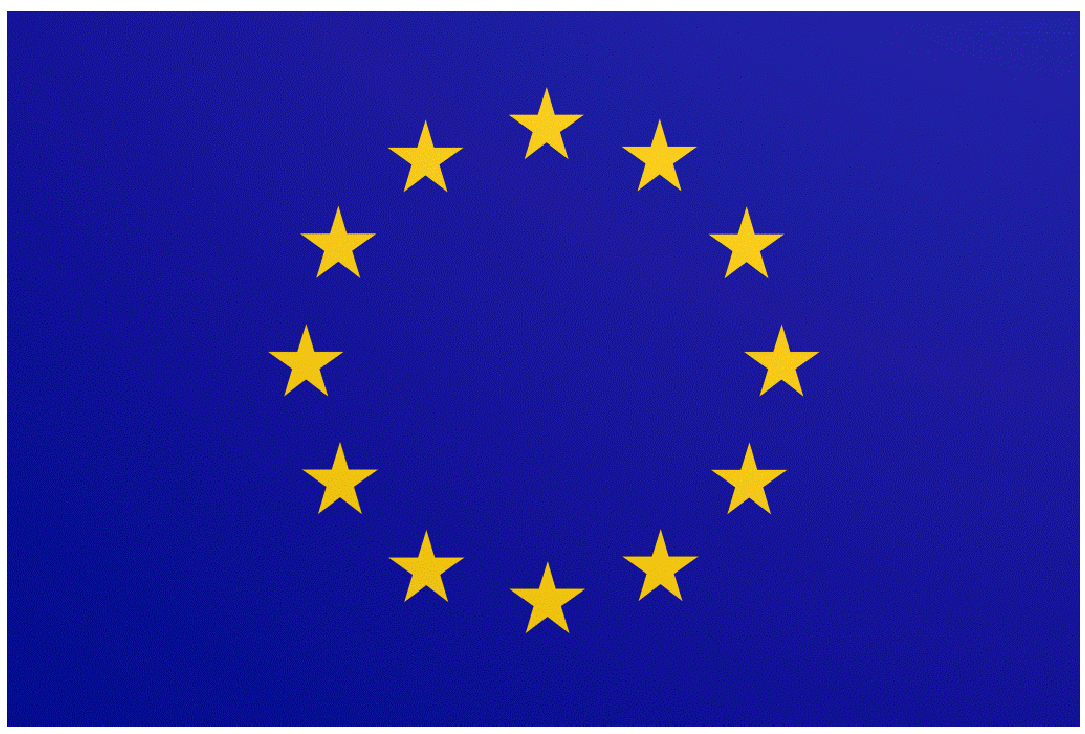

Lund University

Master of International Marketing and Brand Management

Master Thesis

May 2006

Authors

Angelika Kuschel

Vanessa Pieterse
Supervisors

Cecilia Cassinger

Peter Svensson 


\begin{abstract}
The growth of supra-national organizations, such as the European Union, has been a recent trend in today's global environment, which has challenged traditional marketing concepts and product cues. One such cue that is significantly challenged is the 'origin cue'. An origin cue is conceived to be a socially constructed notion that consumers use to discern where goods come from and to accordingly evaluate products with. The origin cue is often predominantly materialized in the public sphere by a 'made in' labelling scheme.
\end{abstract}

Various theorists have proven that the origin cue is a viable source of competitive advantage. Yet, globalization has appropriated and confused such cues and this has accordingly affected the way consumers attribute meaning and process new constructs, such as supra-national origins.

The European Union, which exists at a supra-national level, is currently proposing to introduce a single origin marking scheme - a 'made in the EU' label - to capitalize on this 'competitive advantage'. This umbrella labelling scheme throughout the EU is proposed to improve the visibility and equity of the Union and communication to consumers. Yet, consumers' perception of the viability of such supra-national origin umbrella marking schemes has not yet been consulted, nor has the equity of the 'made in' label at a supra-national level.

The purpose of this study therefore is to determine consumers' working meanings attributed to such a supra-national origin marking scheme. A situated 'global' consumer approach is taken to analyze consumers' perception of the viability of stretching the origin cue to the supra-national level. This is explored with reference to the illustrative and timely example of the European Union.

Focus groups are used to attain consumer perceptions and access meanings they attribute to stretched origins, materialized through marking schemes. The complexity and corresponding viability of such a scheme is discussed, with reference to certain factors that influence how and what meanings consumers attribute to supra-national 'made in' labels in this globalised environment.

The study proposes that supra-nations are not currently perceived as feasible origins by consumers. This currently renders a 'made in the EU' labelling scheme inappropriate as stretched origins lack heritage and a strong social concept, unlike other 'traditional' origin constructs. This study proposes that the origin cue has decreased in importance at this level and its emphasis has been shifted, as it is increasingly difficult for consumers to attribute meaning to origins at stretched levels. This has the implication that such schemes are currently commercially unviable until the supra-national 'perception of origin' can be manufactured to consumers. 


\section{Table of Contents}

$1 \quad$ INTRODUCTION $\quad 5$

1.1 Competitiveness, globalization and modern empire building 5

1.2 Trading blocs and origin 5

1.3 Moving towards a single origin using a 'made in the EU' labelling scheme 6

1.4 Country of Origin (COO) Effect $\quad 7$

1.5 Region of Origin (ROO) Effect $\quad 8$

$\begin{array}{lll}1.6 & \text { Supra-national origin, an undervalued ROO } & 10\end{array}$

1.7 Philosophical orientations within the origin cue's research tradition 11

$\begin{array}{lll}1.8 & \text { Knowledge gaps and research question formulation } & 11\end{array}$

1.9 Purpose of the study 12

2 THEORETICAL CONSIDERATIONS 13

$\begin{array}{lll}2.1 & \text { Philosophical standpoint } & 13\end{array}$

2.2 'Origins' as socially constructed entities 15

2.3 The EU as a socially constructed origin 16

3 METHODOLOGY $\quad 18$

$\begin{array}{lll}3.1 & \text { Research strategy } & 18\end{array}$

$\begin{array}{lll}3.2 & \text { Empirical data collection } & 18\end{array}$

$\begin{array}{lll}3.3 & \text { Practical procedures } & 19\end{array}$

3.3.1 Respondents 19

3.3.2 Sampling 19

3.3.3 Conducting the focus groups 20

3.3.4 Realizing the findings 21

3.4 Methodological defence $\quad 22$

3.4.1 Qualitative research strategy 22

3.4.2 Data collection 22

\section{THEMATIC FINDINGS}

4.1 Theme 1 - The nature of the 'EU construct' and the meanings the participants attribute to this construct

4.2 Theme 2 - Origin marking schemes - the 'made in' label 28

4.3 Theme 3 - 'Made in the EU' as an exemplary supra-national origin marking scheme 29 
4.4 Theme 4 - Variables influencing the meanings and equity ascribed to the "made in the EU' label

5 DISCUSSION

$5.1 \quad$ Infancy of this construct 36

$5.2 \quad$ Lack of heritage 36

$5.3 \quad$ Lack of perceived origin 37

$\begin{array}{lll}6 & \text { CONCLUSION } & 40\end{array}$

6.1 The meanings attributed to a supra-national origin label 40

6.2 Contributions and relevance of the findings for the origin literature 41

6.3 Concluding comments 41

$\begin{array}{lll}7 & \text { LIMITATIONS } & 42\end{array}$

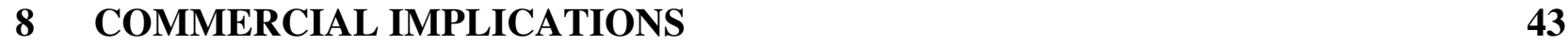

$\begin{array}{ll}\text { REFERENCES } & 46\end{array}$

$\begin{array}{ll}\text { APPENDIX } & 49\end{array}$ 
INTRODUCTION

\subsection{Competitiveness, globalization and modern empire building}

The contemporary fragmentary global environment we inhabit is increasingly encouraging and affected by international trade, on an unprecedented scale. These conditions have had the consequence of inspiring a colossal surge of academic and managerial interest in the new conditions and the products of this environment, and consequently the tools that can be utilized by organizations and even countries to remain competitive. One such trend is the creation of tools such as regional trading blocs. This significant trend in international commerce over the past decades has facilitated, to a degree, the defence against global competition by entering the protective umbrella of regional blocs (Kaufmann, 1972). Such structural configurations have indicated that even nation states have realised the benefits of partaking in the reciprocity of international trade, by surrendering part of their sovereignty to supra-national organizations such as trade blocs. The partaking in such arrangements has implications for the way such nations have been conceived, as places in which entities, such as products, can originate from. Thus the implication of such supra-national arrangements has immense repercussions in terms of traditional conceptions of 'origin' and has confused this concept immensely. Originally, the concept of country of origin was considered as the 'made in' country. Yet, the liberalisation of trade has meant that products not only come from one specific origin anymore, with a definitive image that is apprehensible to consumers, but from multi-locations. The European Union (EU) is a product of this environment, in which arguably to remain competitive, nations and international business must embrace and surrender to.

\subsection{Trading blocs and origin}

The growth of regional trade blocs, such as the EU, has raised questions about how traditional marketing tools can be used in accordance with these new constructs. Traditionally utilised tools such as the 'origin cue' (that is the way products are labelled in terms of their 'origin'), which are extremely relevant to this environment, must be explored and appropriated to this newly constructed environment. Arguably, certain cues such as the origin cue have increased in their relevance and complexity in this environment, compared to their initially conceived applications. Such regional phenomena, characterized increasingly by 'trade agreements' and the consequent 'regionalistic behaviour', have thrown the origin cue into confusion and made it deeply problematic. Economically, it is no longer feasible to be 'true' to a particular origin, but products labelling systems cannot practically reflect this new reality. Labelling products at a supra-national level, such as a 'made in the EU' label, is hypothetically one way to communicate and represent comprehensibly a clear origin to consumers.

Labelling products under this umbrella also foreseeably has the potential to keep trade blocs competitive in the global market. Arguably, not only has the origin cue become extremely relevant due to these socially constructed supra-national 'origin' shifts and formations, but as hegemony needs to be maintained by countries in this globalised trade environment, a plausible way to compete and be competitive is through regionalism and the manipulation of such cues. This can be inferred from early empirical research on the 'origin cue' in marketing.

Consumer research has indicated that there is a clear 'country of origin effect' on consumers' evaluation of products and services; that is its application can be a source of competitive advantage (Schooler, 1965). From this central premise, the origin cue has amplified, been 
'confused' and applied further with the growth of international trade. The EU is a prominent example to explore the origin cue's possibilities for appropriation in response to such 'regional phenomena'. That is the origin cue's possibilities for appropriation or stretching to the supranational level in terms of how it is visible to consumers, as an explicit origin marking scheme.

\subsection{Moving towards a single origin using a 'made in the EU' labelling scheme}

The European Union, as mentioned, is a unique structural construct, characterised by the logic of protective regional umbrella trade blocs. It is an intergovernmental and supra-national union which was formally established by the Maastricht Treaty in 1992 (Littler and Schlieper, 1995). As of today, it is comprised of 25 democratic member states, sharing a common single market ${ }^{1}$. The EU distinguishes itself from other supra-national trade blocs through a political project federalism - which is attached to the establishment of the economic trade bloc. In 2003, the European Commission submitted a working document on the consideration of an EU origin marking scheme for goods, responding to a renewed interest in the issue shown by some industry sectors and member states. This proposal would entail a 'made in the EU' origin label (for a hypothetical illustration see Appendix 1$)^{2}$. Hence, the EU can currently be conceived as a truly timely example of stretching origin to a supra-national level.

The Commission's proposal argues that the anticipated 'EU origin mark' could introduce greater homogeneity and clarity by providing an EU-wide common instrument, setting a harmonised framework for the use of origin marking (be it voluntary or compulsory). It furthermore believes that the origin mark will promote image and attractiveness of EU products, where 'EU origin' is perceived by consumers as being synonymous with superior quality, reliability or style. This attempts to promote 'made in the EU' as a mark of quality and distinction. This is not only expected to improve the visibility of the EU as a single market, but also to improve consumer information.

Some concerns about this proposition were raised by the industries, such as - the 'made in the EU' origin label would not be an acceptable replacement for respected national marks, and that it would not add value since there is no knowledge base of the EU as a whole. Since the internal market is not a country, it is not utilised as easily to provide a clear indication on the origin of a product. It is currently a vague concept, exemplified by the fact that even if the final product is made in the EU, with foreign components, assembly, manufacturing facilities and labour, non preferential rules of origin would allow the product to be marked as being of EU origin.

These concerns reveal that from an organisational level, there are many difficulties with such a proposition. Arguably, before such a proposition was introduced, consumer opinions should have been consulted, as the actual viability of such a scheme and its corresponding success depends on consumer responses and not only on the acceptance at the industry level. Questions should initially be directed at the attributes, meanings, values and equity that consumers subscribe to this

\footnotetext{
${ }^{1}$ The most significant EU institutions are the 'Council of the European Union', the 'European Commission', the 'European Court of Justice' and the 'European Parliament'. The European Union's activities cover all areas of public policy, from health and economic policy to foreign affairs and defence. However, the extent of its powers differs greatly between areas. Depending on the area in question, the EU may therefore resemble a federation (e.g. on monetary affairs, agricultural, trade and environmental policy, economic and social policy), a confederation (e.g. on home affairs) or an international organisation (e.g. in foreign affairs) (Littler and Schlieper, 1995).

${ }^{2}$ Whilst some commercial organisations may be using a variation of the 'made in the EU' label, this is not currently done in any official or large scale sense, as this proposal from the EU plans to instigate.
} 
concept. This would help to assess the potential success of such a supra-national origin marking scheme and its actual empirical effects.

To analyse this feasibility, it is first important to analyse how consumers conceive and evaluate origins and whether supra-national origins, such as the EU, can be conceived as a viable origin. Accordingly, the effects and implications of stretched meanings and the value that consumers attribute to them must be discussed. Hence it is of importance to firstly locate the origin cue in a research tradition- what is the 'country of origin' effect and how has it influenced and impacted studies of 'region of origin' and its effects.

\subsection{Country of Origin (COO) Effect}

The origin cue's theoretical establishment can be traced back to early empirical research into the country of origin effect, based on Schooler's (1965) foundational research, which revealed that the COO effect does exist and affect consumers' perceptions of a product. This early empirical research involved manipulating products with fictitious 'made in' labels signifying various South American countries. The research indicated a consumer bias towards the less developed countries represented in the cluster. Over the last 40 years, the construct of 'origin', from this most 'rudimentary' premise that $\mathrm{COO}$ is a variable or 'a cue' that affects consumers' constructs and perceptions of products, and accordingly they way they discriminate products (Schooler, 1965), has become increasingly problematical. This is due to the fragmented, hybrid and global contemporary environment that consumers engage with and inhabit. 'Product $X$ ' can now hypothetically have its central headquarters and ownership in Paris, be designed by a team of designers from Estonia, with parts sourced from Thailand, be manufactured in Korea, with final assembly in New Zealand and be distributed from South Africa. This example illustrates the increasingly problematical nature of 'country of origin' today, let alone the term 'origin' itself.

Blatant fragmentation of 'country of origin' has become particularly prominent and is considered 'strategic' in the contemporary business and trade climate. This state of confusion has meant that various theorists have accordingly conceived $\mathrm{COO}$ to mean different things and have examined its effects correspondingly. Various definitions of COO have even been polar opposites such as - the corporate headquarters and marketing centre of the brand (Ozsomer and Cavusgil, 1991), or the country of manufacture or assembly (Papadopoulos, 1993). It has also been articulated for some brands that such an origin does not even have to be revealed explicitly; COO is perceived as 'implicit' for certain brands such as Sony and Barilla, throwing the construct into even greater confusion (Samiee, 1994). For the purposes of this investigation, it is vital to explicitly note the defining standpoint of this research, which utilizes the term 'made in' to denote the explicit origin marking label 'made in $\mathrm{X}$ ' as opposed to the processes associated with the label.

Previous research on the manipulation of the single origin cue, at the nation level, has shown that various factors have impacted the evaluation of the origin cue and its apparent 'complexity', which are even apparent at the country level. Consumers have been found to use 'bias' (Schooler, 1971) and stereotyping (Reirson, 1967) when they are evaluating products on the cue of COO. Research has also indicated that demographic, socio-cultural and product class variables influence the significance of the single COO cue and its effects (Dornoff et al., 1974). Nagashima (1970) also found that the evaluation of 'made in' was affected by the familiarity of the product in question and the availability of it to consumers. The findings of Darling and Kraft (1977) supported that actual 'knowledge of the country of origin' affected significantly the perceptions of consumers' evaluations of products. It was also found that it was difficult for consumers to differentiate between products if they had a low familiarity of them. This facet is illustrated by a 
study of American consumers, who were unable to differentiate and attribute value to various ski resorts in European countries due the lack of familiarity with the product/service. Hence, the results here proved to be relatively homogenous (Ofir and Lehmann, 1986).

Han (1989) revealed that the role of 'country image' on consumer evaluations can be either, or both of the following options. Firstly, consumers can use their country evaluations as a 'halo construct', in which country image biases and stereotypes are used to evaluate products that consumers have little knowledge about or low familiarity with. Secondly, it can be used as a 'summary construct' (in addition or alone to the first halo construct). This means that as consumers become familiar with a country's product, country image may summarise beliefs towards the product in question and towards their attitude of the brand. As the market becomes increasingly saturated, the use of such a summary construct has become increasingly important. Han's (1990) empirical research has hence indicated that the 'consumer halo' affects consumers' attitudes to brands and products with various 'made-in' associations and can create a 'summary construct', once a degree of familiarity in place. It also affects intentions to purchase brands from various countries and the perception of a product's attributes. This theoretically functions the same way for regions. Arguably, this is why consumers purchase goods from domestic markets (high familiarity), or countries that have similar economic, political and cultural belief systems (Han, 1990). This also accounts for various stereotypes in terms of developed and less developed countries.

The significant factors referred to above in the $\mathrm{COO}$ effect research tradition are of particular importance to the Region of Origin (ROO) research, as it is assumed to rely on many of the same premises, which have been transferred from this research tradition.

\subsection{Region of Origin (ROO) Effect}

Surprisingly, there has not been a significant amount of research in the literature on 'region of origin'. ROO has been shown to have similar effects to COO (Papadopoulos 1993, Smith 1993), except that possibly, such a greater 'mass' can be more stereotyped and perhaps prone to a greater degree of bias, despite whether this is positive or negative. Conceivably, for a region in question, this can have immense positive or negative implications which involve numerous risks (the potential of the 'halo effect' is amplified). Yet, it is possibly foreseeable that as trade blocs are becoming more prominent, throwing the already problematised concept of COO into greater confusion (that is being used in ROO), more research will have to be done specifically in this field.

Initial enquiries are beginning to surface with regard to this phenomenon. Ittersum et al. (2003) has investigated the image of a product's region of origin on its evaluation by consumers. The basic assumption made here is, that whilst the majority of literature on $\mathrm{COO}$ effects can be transferred to ROO effects, as this is the majority of literature that exists concerning the origin cue, certain differences and unique aspects of ROO must be acknowledged in investigating this construct. Firstly, that ROO can be compared to a branding strategy more so, and that marketers should exploit the associations that consumers have with an area. Yet, this assumption assumes that regions are more homogenous than countries and that the images they convey are internally consistent. This assumption reflects that the majority of the research in this area has framed region at a micro level existing within the country level, for example the Champagne (Ardenne) region in France, with a distinct clear set of natural and/or human environmental values and stereotypes. 
Some prominent examples of 'micro-regional' studies have involved investigations of consumers' willingness to pay for regional labelled products, such as wine (Dimitrius and Aleka, 2002) and the examination of the producer's construction of quality through specialty regional products such as food (Ilbery and Kneafsey, 2000). In fact, such equity and value is placed on certain products' regional status, that over 500 European products have a protected destination of origin status (PDO), meaning that these products must be 'prepared and sourced' from their 'original location/s' (Ritson, 2003).

Even more meagre research has been done on examining the regional construct, its effects and equity at a more 'macro level' (see Figure 1 for various levels of origin stretch). Prominent examples include Smith (1993), who examined consumers' perceptions of products from the regions of Africa, Latin America, Asia and Western Europe. Results indicated that labelling regionally could overcome negative bias about developing countries. Earlier examinations of COO effects have revealed bias of products originating from Asian or African countries. Respondents in this 'macro regional level' study rated products from Africa and Asia as superior or at least comparable to 'Western Europe' (Smith, 1993).

Schweiger et al.(1995) have examined consumers' perceptions of products labelled 'made in Europe.' They compared consumers' perceptions of this construct to Europe's main competitors on the world market, that is conceived here as USA and Japan. In order to fulfil the purpose of the research, Austrian consumers were recruited to evaluate various products' quality, with just the origin cue manipulated in various product categories. The study indicated that consumers perceived the products labelled 'made in Europe' to be evaluated more highly or at least the same as other products. The study indicated that hence 'made in Europe' was a competitive label, with the only hindrance being consumers' perceived variation in the various countries' competencies to produce certain products, across the various product categories.

Figure 1

The various theorized levels of origin stretch

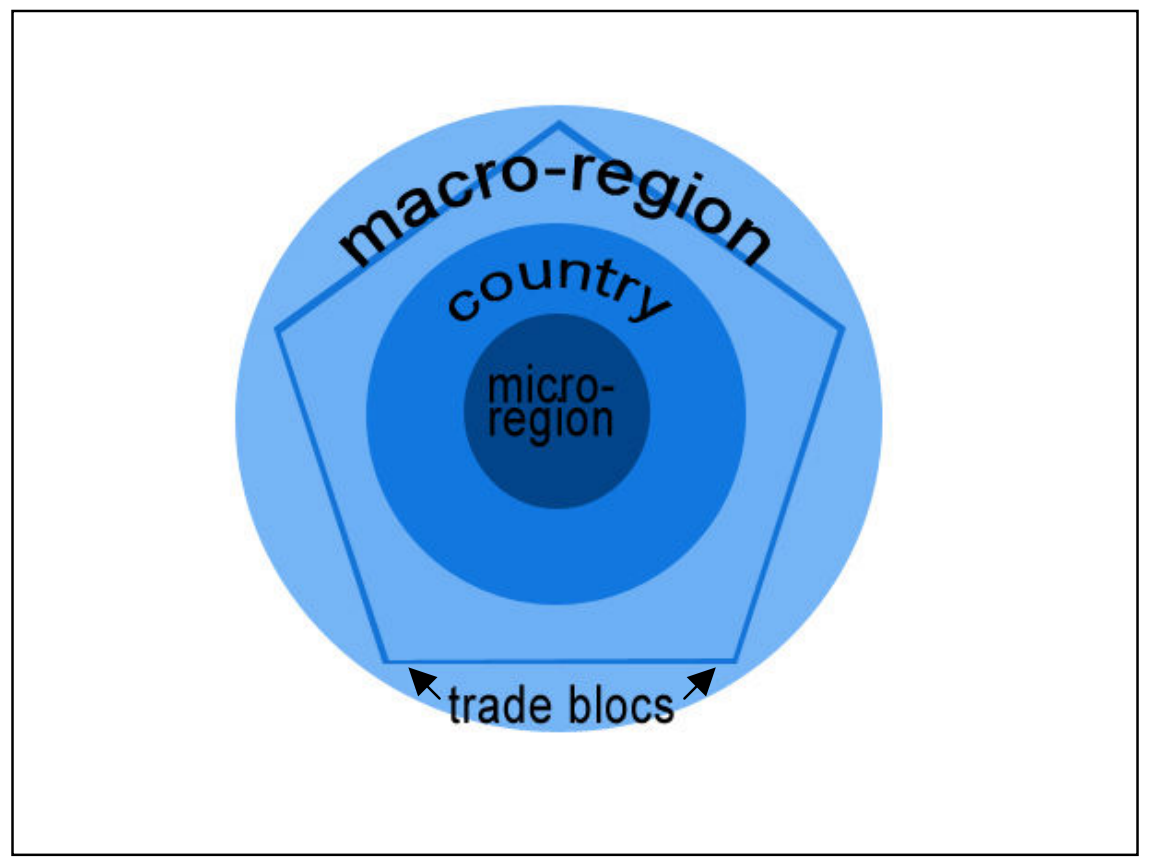




\subsection{Supra-national origin, an undervalued ROO}

Trade blocs though in this research tradition still appear to be largely uncharted territory within macro-regional studies, due to their temporal infancy, compared to the other constructs analysed within this tradition. Research into the stretched supra-national origin, and the meanings attached to it, is still ultimately unexplored. Some initial examples include Papadopoulos (1993) who has examined consumers' perceptions of regional trade blocs, and the consequent development of trade blocs. Papadopoulos (1992) has discussed extensively the emergent role of trade blocs for marketing strategies, and suggests that in terms of such strategies, there are implications for tradeblocs that differ from more common perceptions of origin for consumer products, such as at the national and global level and also at the 'regional level', where no such associations exist.

Papadopoulos (2002) argues that marketers have neglected attention to trade blocs and regional integration trends, ignoring their expansion and importance in commercial life, tending to usually apply 'global strategies' across regions. It is argued that marketers have tended to be more concerned whether there is an absence or presence of commonalities between countries, rather than the implications of formal trade blocs. When studies are done in these areas, he argues that they are mainly done from an intra-consumer perspective, looking at that specific trade community and participants within it. He argues that such trends are likely to increase in importance, as trade blocs are likely to evolve into even larger institutional structures. A marketing implication for the emergence of such trade blocs is not to apply 'national' or 'global' strategies but rather specific 'regional strategies'. A point of difference though also exists within marketing strategy at this 'regional level'; interested parties need to be aware about the impact of formal integration on 'regions', in the form of trade blocs and the effects of this on consumer behaviour. Whether trade blocs result in the homogenization of consumer preferences, and if so, should brands be repositioned accordingly, this possibly involves some comparative study between area studies and trade bloc studies (Papadopoulos, 2002). Most important marketing implications are going to result in the combination of regional characteristics and consumer preferences in trade structures that create demands for unique marketing mix strategies- in the product area, in the pricing strategy, in distribution and in promotion (Papadopoulos, 2002).

Heslop and Papadopoulos (2002) in, "Who controls the purse strings- A study of consumers' and retail buyers' reactions in an America's FTA", explore consumers' and retailers' perceptions of products from Canada, US, Mexico, Argentina and Chile (members of the NAFTA and proposed members of an America's FTA). The article argues that the success of such trade blocs relies on consumers' attitudes towards the countries in them. Arguably the willingness to buy goods is related in this study to consumers' views of the products and the people at the country level within the trade blocs. The study also examines perceptions of retailers and consumers only from one country within this NAFTA construct, there is no comparative perspective from the 'inside and the outside'. The study does not examine consumers' perception of the brand equity of the NAFTA construct itself, but only at the individual units within it. It argues that with such divisions, trade and individual business are not at its full potential and lessen the impact and the point of certain trade agreements, if they are not valued by certain consumers and retailers, mostly from countries with greater purchasing power. That particular study did not view the trading bloc construct as an integrated whole.

Another prominent study on consumers' perceptions on the development of trade blocs is the effects of 'consumer cringe' (Rugimbana et al., 2000) Consumer cringe is equivalent to negative COO effects (consumer cringe can also work the other way although perhaps not so aptly named). The study examines the effects of regional trade blocs, such as EAC (East African Co-operation) compared to local and Western products from a consumer perspective, again the effects on 
consumers within this trade bloc. No study within this tradition has explicitly looked at the possibilities of an umbrella origin label, that is the 'made in'.

\subsection{Philosophical orientations within the origin cue's research tradition}

Most researchers in the origin cue research tradition have undertaken a positivistic approach, as the best way of obtaining knowledge about the origin cue. Studies in this research tradition have predominantly used random sampling techniques (Nagashima, 1970), such studies have also predominantly involved quantitative questionnaires (Greer, 1971 and Dornoff et al., 1974) and predominantly asked consumers to evaluate products according to certain scales, such as semantic differential scales (Nagashima, 1970).

In contrast to this methodological and philosophical history, Ger et al. (1999) have examined the origin cue in an interpretative manner. Such an approach is taken here with the COO effect and the consequent examination of product place images (PPI) as a contextualized, experiential and as a socially constructed notion (as is taken in this research approach). Ger et al. (1999) argue that such an approach is appropriate as countries and nations engender mythological narratives and constructed images, on the 'self and the other' which begin a signification process mainly centred on stereotypes which result in notions such as 'foreign and domestic', 'country X-country Y'. They specifically argue that this contextual experiential understanding of product - place images or a COO effect is dependant on contextual dimensions of place, product, market context and usage context (1999). That is, a product origin tells stories that are contextual, which result in multiple realities and meanings associated with a fixed origin.

Origin hence can be conceived as a highly fluid and constructed notion. Ger et al. (1999) argue that many current conceptualizations and measurements of $\mathrm{COO}$ do not capture the contextual and comparative nature of meaning that is required when investigating such phenomena, a rich contextual approach is argued to be needed to effectively capture this. Such stereotypical and experiential images are argued to be socially constructed and become part of a signification process. In this process, origin meanings are determined through the connotations they evoke, that is 'origin' can largely conceived as a myth (Ger et al., 1999).

\subsection{Knowledge gaps and research question formulation}

Hence it is possible to discern certain knowledge gaps in which this study can contribute to the body of knowledge of ROO, which is significantly scarce compared to the amount of literature that exists on $\mathrm{COO}$ effects. This study more specifically sets out to examine the 'effects', in this sense the meanings, of stretching origin to the supra-national level, which is a niche and particularly unexplored facet of ROO effects.

In terms of knowledge gaps within the origin cue's conception, as stretched to a supra-national level, no research attempts to explore the notion of a trade bloc as an integrated entity in a holistic sense, which is the actual equity of the holistic construct on its own. Even if other studies have examined it as a quasi-holistic construct (that is compared to other constructs, not as an entity in itself), they have not examined the potential of such an origin marking scheme to represent the supra-national origin cue to consumers. Arguably this is because no such proposition, such as the EU's current working document proposing such a scheme, has been so publicly put forward before. This analysis also attempts to differentiate itself by doing a situational study of the EU (an 
unexplored case) and by taking a global consumer approach. The most appropriate way to explore this origin stretching is taken here to be through a social constructionist consumer oriented approach, to facilitate engaged meanings. This is highly relevant as to date there is no indication on how consumers evaluate or attribute constructed meanings to supra-national origin labelling schemes, such as the EU's current proposal, and the implications of this for the origin cue. This is what makes this study truly a pilot project.

\subsection{Purpose of the study}

The purpose of this study is to hence explore the meanings attributed to a supra-national origin label and the perceived viability and implications of this. This will be explored by examining the meanings consumers attribute to the EU as a construct in itself, and as a hypothetical origin. This will be done to attain a variation of working perspectives on how the 'made in the EU' label is conceived by a range of situated consumers, geographically and through 'in and out groups'. 


\subsection{Philosophical standpoint}

This study is based on an explicitly social constructionist ontological approach, as it is examining the ways a certain phenomenon and its meanings are constructed in the social sphere by social actors (Bryman and Bell, 2003). In this light, a social constructionist approach is deemed an appropriate philosophical standpoint, as it suggests that reality exists through the meaning that is attributed by people, with meaning being 'constructed' by people through shared experiences, conveyed by language and symbolism (Easterby-Smith, Thorpe and Lowe, 2003). Social constructionism understands meanings to be produced in current and contextual social interactions, which produce certain 'versions of reality.' These 'versions of reality' are in a constant state of flux and open to revision, such as the current shifting nature of 'origins' (Bryman and Bell, 2003).

A social constructionist ontology suggests that certain philosophical assumptions are appropriate to attain knowledge regarding the nature of reality, social beings and knowledge (Hudson and Ozane, 1988). In terms of the 'nature of reality', a constructionist approach denies the existence of one objective reality, rather this philosophical assumption suggests that reality is created by individuals to help make sense of their worlds, through creating categories and theories about 'a reality', which is maintained through social interaction. Through this social interaction, reality is mutated and transmitted, resulting in various realities (Berger and Luckman, 1967 cited in Hudson and Ozane, 1988). As these 'multiple realities' are apparent and acknowledged by constructionists, knowledge and meaning is ultimately assumed to be contextually based and hence participants should be observed in their natural context and viewed in a holistic sense, as meaning from this perspective only gains meaning through other systems of meaning (Lincoln and Guba, 1985). Reality hence is not assumed to be something that is externally inflicted, but rather seen as emergent, continually being constructed and reconstructed. Meaning hence is seen to be primarily built upon interaction, and as highly ephemeral, related to a specific time and place (Bryman and Bell, 2003).

As conceived by a constructionist viewpoint, it is extremely important to be reflexive about the role that informants take in the research and how they can be conceived to 'be situated' within 'their reality'. In line with the constructionist philosophical assumption, individuals are active producers of meaning, which results from their interaction within the social world (Blumer, 1980 cited in Hudson and Ozane, 1988).

Constructionists' goals for research are explicitly based on a process of gaining understanding of a construct and the meanings attributed to it. This process of gaining understanding of meaning/s is reflexively argued to be a hermeneutic circle, as ultimate understandings can never be achieved, but certain situated understandings are desired. A problematic in the goal of such research is the extent to which 'Verstehen' can be achieved. According to Wax (1987, cited in Hudson and Ozane, 1988), this term refers to the ability to adequately grasp shared meanings, within a specific culture, context, role and language. Arguably, to gain such 'Verstehen', sometimes the researcher has to drop the assumption of shared meanings to achieve a complete understanding (Hudson and Ozane, 1988). Constructionist research is directed at generating knowledge; this perspective focuses on as many variables and contextualized details as possible, leading to greater and thicker descriptions (Hudson and Ozane, 1988). This often means that this type of research is geared to discussing meanings and patterns within a context, which are often difficult to generalize outside that specific context. 
Within constructionism, there are various emphatic approaches that can be taken within this generalized 'world view'. For the purposes of this social enquiry, the specific epistemological standpoint lies on a spectrum somewhere between Clifford Geertz's interpretative approach and Herbert Blumer's symbolic interactionist approach, to gain a richer understanding of the meanings attributed to a supra-national origin. Geertz's (1973) perspective suggests that understanding is achieved, albeit a 'constructed understanding' through a process of interpreting 'thick descriptions'. For Geertz, the research then must be a process of capturing and hence interpreting vivid images, meanings and experiences. A pertinent point concerning Geertz's work is that he focuses on cultural collective meaning from 'thick descriptions' which is relevant to this research. By grouping the participants into geographical clusters (Africa, Asia/Pacific, North America, and EU), it will be attempted to increase the variation of meanings attained, but to also see if there is a particular understanding or a 'collective consciousness' resulting from the phenomenon of the 'EU as an origin', that affects these parties directly or indirectly. Yet, a common criticism within the work of Geertz and his philosophical assumptions (as is with this research approach) is the boundaries within specific contexts. For example, when does the breath of a common cultural understanding begin and stop (Hudson and Ozane, 1988). But if meaning is attained in an individual and collective sense, a meaning cycle of refinement is evident that results from interacting within society. If meaning therefore is interpreted from a collective sense, it does not ultimately undermine the constructionist project. Hence, the way that individuals interact within these groupings and how they collectively produce meaning, is valued within this research.

Along this line of thought, Herbert Blumer of the symbolic interactionism school of thought, (who primarily favours the individual actor) also accounts for the collective interaction which produces individuals' interpretations (Blumer, 1980 cited in Hudson and Ozane, 1988). Symbolic interactionists argue that interaction takes place as the individual is continually interpreting the world, and that the symbolic meaning of their environment which includes the actions of others is way meaning is imputed (Bryman and Bell, 2003).

Blumer argues that there is an 'objective reality' that affects human beings. In the case of 'origin' it can be conceived as an objective reality in the sense of a 'geographical location', or even arguably as a political entity such as a 'nation state' (Blumer, 1980 cited in Hudson and Ozane, 1988; Bryman and Bell, 2003). Blumer argues that despite the existence of such 'objective reality', the world is primarily known by actors in the way it becomes to be perceived by them, such as socially constructed origins (Blumer, 1980 cited in Hudson and Ozane, 1988) ${ }^{3}$. This socially constructed reality can shift as actors develop new perceptions of it, for example the redrawing of borders, the stretching of origins or the emergence of supra-national trade blocs (Blumer, 1980 cited in Hudson and Ozane, 1988). He then argues that the relevance of the 'objective reality' comes back, as it operates as a test of validity of these perceptions, against the resistance of the world to these social constructions by social actors. For example, the objective reality that the world is not flat has undermined that previous social construction; the social construction of the world as spherical is not undermined by an objective reality (yet) and hence, that construction is able to co-exist. In this example, the test of validity against the social construction of an origin, that it is the physical reality does not undermine he conception of supranational trade blocs, as ultimately they are socially based, they are supra- pre existing land masses (Blumer, 1980 cited in Hudson and Ozane, 1988).

\footnotetext{
${ }^{3}$ Despite the focus on the active role of individuals in the social construction of social reality, it is admitted under a some constructionists' position, such as Strauss et al. or Becker, that there is a pre-existence of the objects of interest (Bryman and Bell, 2003). Thus, the point is taken that there are existing 'physical land masses' (nation states, as a political entity), which are inhabited by certain groups and turned into imagined 'origins' (social concept of nations as a cultural entity), yet these are always shifting and being reconstructed, especially with the advent of such forces as globalization and integration.
} 
Thus, for the purpose of this study, the assumptions of Geertz and Blumer will be reconciled to study the phenomenon of constructed 'origins', using focus groups to study through the way it affects the individual, the group and 'cultural collective consciousness', in terms of their symbolic interplay with society.

\section{2 'Origins' as socially constructed entities}

The analysis of the selected constructionist literature indicates that the notion of an 'origin' could quite conceivably be looked at as a social construction. An origin is understood to be a place where various entities are perceived to originate from, such as consumer products. Then, an 'origin' can be inferred as 'a reality' that is not external, but constructed by actors from interaction and the meanings attributed by them. This socially constructed nature of origins has been examined by many theorists. Perhaps the most notable work has been done with regard to nations, as social concepts, such as Benedict Anderson's (1991) conception of nations as 'imagined communities'. A social concept is understood here to refer to an explicitly socially constructed entity, created by people situated in society and culture. The majority of literature exists in this body of work, hence the concept of nation as social construction will be analysed, to look at origins as socially constructed.

In defining origin-orientated terms, such as 'nation' and 'nationalism', social scientists have tended to fall into two distinct groupings - the primordialists and the modernists, which both conceive the 'conception of a nation' as a socially constructed entity (Smith, 1995). It is significant at this point to stress that 'nations' as social construction and the idea of nations as 'imagined communities' focus on the social/cultural concept of the nation ('nation') rather than the political ('nation state') ${ }^{4}$. Primordialists believe that the notion of nation rests on a primordial need to belong to a community, and that this need is prior to modernity. In opposition to this school of thought is the predominant contemporary 'modernist' paradigmatic interpretation of a nation (Hitchins, 2001).

Within this 'modernist' paradigm, there are many variations in schools of thought, however the leading exponents, Ernest Gellner, Benedict Anderson and Eric Hobsbawn, agree that the nation is of comparatively 'recent origin' and is a product of modernization (Hitchins, 2001). Dating back to the era of the French Revolution, which - as they argue - introduced the idea of the 'modern nation' (by establishing the principle of the sovereignty of the people), nations are wholly products of the modern age and appear to be a response to capitalism and industry (Hitchins, 2001). Thus, since nations are seen as the result of recent economic, social and cultural changes, they are not deeply rooted in history, but are 'created', that is, imagined and constructed by intellectual elites or other classes, who - in effect - invented the nation's history and myths and disseminated them through books, newspapers, and works of art (Anderson, 1991). Thus, nations as the social concept - were not natural entities existing from the very earliest times, but rather socially constructed.

A widely quoted description of the concept of 'nation' is Benedict Anderson's account of nations as 'imagined communities' - nations as socially constructed and ultimately imagined by the people who see themselves as part of that group (Anderson, 1991). The conception of 'imagined communities' can be seen as a constructed notion on par with Edward Said's concept of 'imagined

\footnotetext{
${ }^{4}$ A nation consists of people "inhabiting a fixed territory, sharing key elements of a common culture (values, beliefs, norms, institutions), and possessing a sense of common interest' (O'Shaughnessy and O'Shaughnessy, 2000 p.56-57), whereas a nation state is a political entity which can possibly be composed of several nations.
} 
geographies'. Anderson looks at nations as an 'imagined political community - that is imagined as both inherently limited and sovereign" (1991, p.6). Anderson defines a nation as imagined because "members ... will never know most of their fellow members...yet in the minds of each lives the image of their communion" (1991, p.6); and limited because "even the largest of them...has finite, if elastic, boundaries, beyond which lie other nations" $(1991, \mathrm{p} .7)^{5}$.

\subsection{The EU as a socially constructed origin}

Mamadouh (1998) proposes the idea that if a nation can be an 'imagined community', then possibly the EU should be conceived as a 'nation', since clearly, the European Communities and European Union have been imagined political communities. This construction has gone so far as to demonstrate that "such an imagination can successfully challenge centuries of national rivalries" (1998, p.12); this is evident in consideration of Germany and France or England and Holland. Mamadouh (1998) suggests that the community building is designed as a way to implement a supra-nationalist program, which is hypothetically modern 'nation formation'. This process may in the future be 'naturally' re-interpreted as the first steps toward a 'supra-European nation', while earlier periods of unification such as the Roman Empire, the Holy Empire of German Nations, Napoleon's Europe and Hitler's Third Reich could be re-interpreted as the 'primordial forerunners' of a European nation. Other theories may not align with such a conceptualisation of the EU as a modern nation, but according to both these philosophical standpoints, there is no reason why supra-national origins can not be imagined as an origin, in a different sense.

Thus, it is arguable that the notion of origin is linked to the socially constructed aspects of a nation, (consisting of people inhabiting a fixed territory, sharing key elements of a common culture and possessing a sense of common interest, rather than the political entity of a nation; O'Shaughnessy and O'Shaughnessy, 2000). Hence it is arguable that 'nations' could be conceived by the social imagination as an 'origin', consequently origins can be socially constructed or imagined. If this can be imagined at the country level, hypothetically, origin can also be stretched to the supra-national or trade-bloc level. Hence, entities such as the EU could be conceived as socially constructed origins theoretically, despite whether this is identified by consumers in 'reality'.

As stated above, one of the main premises of social constructionism is to view the nature of such constructions as being constituted by many realities, which result in the realities' 'holistic picture'. The EU can be imagined as such a hybrid 'reality', that many citizen-consumers experience varyingly from their situated perspective, such as the EU from an Italian viewpoint, the EU from an EU member viewpoint, the EU from an 'other'-ed perspective. This envisaging of a construction, such as a trade-bloc, reflects the symbolic interactionists' project of individuals' experience and negotiation of such a construction, contributing to the holistic view of the construction and the reality of it. In this sense, to understand this holistic reality and see whether consumers identify this construct currently as a meaningful reality, it is extremely important to explore as many situated perspectives as possible, or to try to identify any "collective consciousnesses' of such a construct.

\footnotetext{
5 Other facets of Anderson's definition include the imagined sovereignty and community of a nation. It is sovereign since "the concept was born in an age ... [of] Enlightment and Revolution" (p.7), i.e. an age of freedom of the individual. And a nation is a community because it is "always conceived as a deep, horizontal comradeship" (1991, p.7).
} 
Ben Rosamond (2002) argues that the construct of the 'European Union' can be imagined in various forms, such as in terms of competitiveness, industry and firms, which are not self-evident entities but social constructions, with the articulation of such ideas being the outcome of intense discursive practice. For example, the European Union has sought to imagine Europe as an imagined symbolic and political entity to increase its competitiveness (Rosamond, 2002). EU members cannot exist in a meaningful sense unless it is actively imagined by social actors. It is also argued by Rosamond (2002) that such ideas are played out through rhetorical strategies and are often economically-interest driven; these interests he argues are largely perceptual and subjective rather than fixed by an objective status. Hence, if such interests and ideas are highly flexible and constructed, so must be their perceptions. He argues that such discursive constructions as 'Europe', and arguably the 'European Union', involve the active imagination of subjects who populate the constructed entity (2002).

A large region such as Europe is arguably able to be conceived as an 'imagined' construct by these actors through processes instigated, by the emergent integrating role of socially constructed bodies such as the European Union. Hence Europe, usually conceived by these actors as the EU, arguably has the attributes and identity formation potential among various social actors as a community does (Rosamond, 2002). Hence, arguably, the European Union which is displacing and refining Europe, has the supposed ability to displace or appropriate traditional conceptions of Europe, as an 'origin' with which social actors can affiliate with. Arguably, the community formation ability of such organizations is so strong and all encompassing that it has the ability to redefine national boarders, which certain actors have affiliations to through building community across mass publics, through its integration rhetoric and discursive practice and 'common-sense' discourses with the hypothetical promise of a 'United States of Europe'.

The constructed boundaries of such an 'imagined' notion is being constantly redrawn and reconstructed, through constant interaction with social actors and the social world, whereby hypothetically all identities are mediated by experience and are fluid. Thus, the project by the European Union, the integration and consequent interdependency and identification of various member states, is also directed to various community building activities, in an attempt to get social actors to identify with the project, which has the ability to unify the project itself. This relies on using deep symbols and images and creating a political culture that is capable of giving a substantial 'core matter' to create a unified civic identity (Rosamond, 2002).

Yet, in the globalised contemporary consumer society, such a collective identity or community and its products cannot be confined easily by boundaries nor is this desired for such entities to be competitive. In terms of marketing consumer products, not only should the 'self' identify with the symbolic values of the constructed origin, but the 'other' must also (Rosamond, 2002). To be competitive and profitable, the other must desire the symbolic, constructed values of the self. This not only affirms the identification and integration of the 'selves' but also the desire to belong to the 'other' arguably. Hence, marketing an exclusive community such as the European Union could prove to be a profitable strategy.

This potential imagery raises many questions, such as- What characteristics make an entity meaningful, or can the transference of historical ideas of 'heroic ideas of Europe' enable a degree of identification and loyalty (Rosamond, 2002). It is furthermore argued that it is not only important to ask if the EU is being imagined as an origin or imagined at all, but to ask whose and which images are being imagined and how are these images prevailing (Shore in Rosamond, 2002). Such questions truly reflect the socially constructed nature of such a construct. 
METHODOLOGY

\subsection{Research strategy}

On the basis of the research purpose to derive meaning attached to supra-national origin marking, and in accordance with the theoretical framework based in the social construction of meaning, it is reasonable that this study is conducted using a qualitative, interpretative research approach. This research sets out to interpret and achieve an 'empathetic understanding' of human action to explain and access the variation and multiplicity of social experience and working meanings attributed to a construct (Easterby-Smith, Thorpe and Lowe, 2003).

Since interpretative research is about reporting interpretations of individuals, attitudes and perceptions, and not about reporting facts (Bryman and Bell, 2003), a qualitative research strategy is to be applied, which is aiming at generating understanding, rather than quantifying the region of origin phenomenon (Bryman and Bell, 2003). Qualitative methods are strong in their ability to understand people's meaning attributed to new ideas, and to contribute to the evolution of new theories (Bryman and Bell, 2003). Thus, what makes interpretative research so attractive is that the research methods focus on the complexity of human sense-making as the situation emerges instead of predefining dependent and independent variables (Klein and Myers, 1999), which is extremely relevant to the goals of this research. Understanding therefore is viably attempted to be obtained in this research through qualitative interviewing. Qualitative interviewing generates a context that attributes interest to the participants' view point, allowing them to give rich detailed accounts of their experiential meaning (Bryman and Bell, 2003). The flexible context created allows participants to 'go off on tangents' regarding what they determine subjectively as relevant information (Bryman and Bell, 2003). Due to the research being interested in the collective production of meaning attributed to origin marks, focus group discussions were considered to be the most suitable data collection method.

\subsection{Empirical data collection}

The focus group method under the umbrella of qualitative data interviewing is considered relatively feasible to execute, taking into account the goals and parameters of this research. It is a form of 'group interview' that departs from the viewpoints of the participants (Bryman and Bell, 2003). Focus group discussions emphasise questioning on a fairly tightly defined topic, such as 'made in the EU' as a supra-national origin label, and encourages the dynamic construction of meaning through interaction in a group (Bryman and Bell, 2003).

Focus group discussions furthermore put an accent upon the collective construction of meaning (Bryman and Bell, 2003). It is a central tenet of the underlying theoretical position that 'understanding' is not undertaken by individuals in isolation from each other, but rather it is something that occurs in interaction and discussion with others. In an individual interview, the interviewee is often asked about her or his reasons for holding a particular view, but the focus group approach offers the opportunity of encouraging participants to probe at each others' reasons for holding a certain view (Bryman and Bell, 2003). Individuals can challenge each others' views which results in more realistic accounts of participants' perspectives since they are forced to think about and possibly revise their views (Bryman and Bell, 2003). The resolution of disagreements also helps to oblige participants to express the grounds on which they hold particular views. In this sense, focus groups reflect the processes through which meaning is jointly constructed in everyday 
life, and to that extent can essentially be regarded as more naturalistic than individual interviews (Bryman and Bell, 2003).

\subsection{Practical procedures}

\subsubsection{Respondents}

Nineteen volunteers participated in the present research, eight of which were female and 11 which were male, with a mean age of 23.4 years. The participants' demographic characteristics are summarised in Table 1. Participants were current students at Lund University, and were from different countries within and outside the EU. Out of 26 people approached for recruitment into the study, 19 participated, yielding a response rate of $73 \%$.

\section{Table 1}

Focus group participants

\begin{tabular}{|c|c|c|c|c|c|}
\hline Focus Group & Name & Age & Gender & Country & Studies \\
\hline \multirow[t]{4}{*}{ Asia/Pacific } & Andrew & 20 & male & New Zealand & Political Studies/ Law \\
\hline & Sarah & 20 & female & Australia & Commerce \\
\hline & Fang & 22 & female & China & Asian Studies \& Intl. Marketing \\
\hline & Toby & 24 & male & Australia & Business \\
\hline \multirow[t]{5}{*}{ North America } & Danny & 20 & male & Canada & Business/Accounting \\
\hline & Pierre & 22 & male & Canada & Economics \\
\hline & Mitchell & 26 & male & Canada & Biotechnology \\
\hline & Charlie & 26 & male & USA & Law \\
\hline & Shelley & 21 & female & USA & Engineering \\
\hline \multirow[t]{4}{*}{ Africa } & Mandisa & 25 & female & South Africa & Law LLM \\
\hline & Jahi & 31 & male & Kenya & Remote Engineering (RS) \\
\hline & Ade & 25 & male & South Africa & Remote Engineering (RS) \\
\hline & Habibu & 28 & male & Ethiopia & Remote Engineering (RS) \\
\hline \multirow[t]{6}{*}{$\mathrm{EU}$} & Kurt & 19 & male & UK & Politics \\
\hline & Stephanie & 22 & female & Germany & Economics \\
\hline & Lida & 23 & female & Czech Republic & Law \\
\hline & Francesca & 20 & female & Italy & Languages \\
\hline & Pablo & 26 & male & Spain & Engineering \\
\hline & Lisa & 25 & female & Finland & Law \\
\hline
\end{tabular}

\subsubsection{Sampling}

Since measuring or evaluating each member of a population is habitually unfeasible, a universal technique, sampling, was used to select a small subset representing a given population in attempt to generalize results and conclusions for the entire population (Lundsford, 1995; Bryman and Bell, 2003). This allows a smaller number of researched subjects, which was considered appropriate for the scope of this research. Potential bias in the participant selection possibly lead to errors in 
interpretation of results and arguably decreases the generalizablilty of the results beyond the studied subjects.

The population under examination were consumers from in- and outside the European Union. Cox and West (1986) define a population as a group of people or objects that share common characteristics, in this study it is a common geographical area. Consumers were recruited from Africa, North-America, Asia-Pacific and European Union member states. The respondents were all students, both male and female, and currently enrolled at Lund University. The respondents had to be English speaking, at least as a foreign language, since the focus groups were conducted in the English language. There were no inclusion criteria concerning age. This sample is arguably biased by the fact that all participants were currently enrolled at a Swedish University, and were consequently all living in an EU member state. This common characteristic suggests some degree of familiarity with Europe and the EU.

When defining a representative subpopulation, it is possible to use a 'probability' as well as 'nonprobability' sampling method. The more feasible method for this study that aligns with the goals of this research is convenience sampling, a non-probability method with a non-random sample. Convenience sampling allowed the researchers to select participants simply because of the convenience of their accessibility (Lundsford, 1995). However, it is not suggested that the sample fully represents the target population, because the sample selection is likely to have been biased by the researchers' personal judgment, and by prospective respondents' accessibility and availability (Bryman and Bell, 2003). Recruitment techniques included personal contact via phone or email and some home visits at the international housing Spoletorp North. During these initial contacts, a brief explanation of the research was given. Because participants were personally approached by the researchers or by other participants through snowball sampling ${ }^{6}$, this method turned out to bring about a good response rate.

\subsubsection{Conducting the focus groups}

The focus group discussions were conducted between April $28^{\text {th }}$ and May $5^{\text {th }} 2006$ in Lund, Sweden. The researchers conducted four focus groups, one with students from African countries, another with student from EU countries, as well as one with students from Asia/ Pacific and lastly one with North American students. Three of the four focus groups were conducted in the living room of one of the researchers' house, which was conveniently located in the centre of Lund. The other focus group, the EU group, was conducted in an international housing residence, as it was the home of four out of the six participants and therefore convenient for the respondents. The focus group discussions were an average of 90 minutes each, and were conducted by both researchers. The participants were welcomed and introduced to each other, offered refreshments, and asked permission to audiotape the sessions. Any identifying names or references were replaced by pseudonyms.

Most participants knew each other, which greatly facilitated the natural flow of the conversations. Approximately 45 minutes of each focus group's duration was spent discussing the meaning of origin marks in general, the EU construct, and subsequently a 'made in the EU' origin mark. The remaining time was spent on the group exercise that the researchers prepared.

\footnotetext{
${ }^{6}$ With this approach, the researcher makes contact with a small group of people who are relevant to the research topic and then uses these to establish contacts with others (Bryman and Bell, 2003).
} 
The group exercise included 16 unbranded products (without any other visible cues), printed on cardboard signs. The products were from various product categories such as food, apparel, accessories, furniture, cosmetics, pharmaceuticals, as well as mechanical and electrical products. In a group effort, the participants of each group were asked to arrange the products according to their suitability to an EU origin marking scheme (see appendix 2 for visual representation). This exercise was designed as another means to overcome the tiring demands of the focus group. The goal was to access a greater variation of meanings attributed to products labelled 'made in the EU'.

The primary intention of classifying the respondents into four regional groups was not to allow a cross-group comparability, but to elicit a wider variety of different views in relation to this particular issue. The researchers used a few general questions (standard across the focus groups) to generate initial reactions in a relatively open-ended way and to further stimulate the discussion and the exercise. This open-ended approach with only a modicum of structure was necessary since the researchers knew little of the consumers' perspective on the EU as an origin construct (Bryman and Bell, 2003). The number of participants per focus group varied from four to six individuals, which Bryman and Bell (2003) consider to be very small groups. However, Morgan (1998a cited in Bryman and Bell, 2003) argues that smaller groups are suitable when topics are controversial or complex and when gleaning participants' personal accounts is a major goal.

Since it is quite difficult to write down 'what', and particularly 'how' participants responded in this environment, the sessions were tape recorded in agreement with the participants. Tape recording facilitated the researchers to document who expressed views, who was the opinion leader, and who did the range of opinions derive from. When interpreting the data, transcribing allowed the researchers to take into account interaction within the group, cite, or draw inferences from patterns of interaction within the group (Bryman and Bell, 2003).

\subsubsection{Realizing the findings}

After all four focus group discussions had been conducted, the researchers together transcribed parts of the recorded discussions. It was decided to transcribe only sections of the focus group discussions, since some parts were unlikely to be fruitful. While listening to the tapes, both researchers took notes on important issues that the discussions touched upon. Furthermore, interesting arguments and claims which were considered to be of importance were written down in exact wording of the participants to possibly use them as illustrative quotes. (A few times, the arguments were of such length that it was agreed upon that the exact wording will be confirmed by listening to the tapes additional times, but only after it was certain that they will be used in this report since it was extremely time consuming.) The time spent on transcribing the four discussions (even if only to a limited degree), as well as making sure exact quotation was used in the citations, amounted to approximately 12 hours. After all tapes were listened to, and partly transcribed, each researcher went through their notes, in an attempt to discern certain trends and variations in perspectives. After that, the researchers combined their findings and together discussed what 'thematic categories' could emerge from those findings. Four main thematic categories were agreed upon. Each researcher then went through their transcriptions again to find arguments made by the participants to emphasize these four themes. 


\subsection{Methodological defence}

\subsubsection{Qualitative research strategy}

Despite the anti-quantitative approach of interpretive researchers, even a qualitative study has to provide some criteria of evaluation. Thus, researchers who follow the interpretivist/constructionist paradigm can try to ensure that validity, objectivity, reliability and similar standards are considered and valued in their own context (Sarantakos, 2004). Lincoln and Guba (in Bryman and Bell, 2003) argue that qualitative researchers' concept and theories are representations rather than definite versions of social reality, and that therefore there may be other equally credible representations of the same phenomena. According to them, one way of bolstering those accounts is the strategy of thick description. The use of thick description of how this research was conducted, who the participants were, and how findings and conclusions were derived, is a means of establishing trustworthiness and attempts to ensure that this study can be replicated. The frequent use of citations from the focus group participants is a means for the researchers to show evidence for transparency in how sense was derived from the raw data (Easterby-Smith, Thorpe and Lowe, 2003). Recording the discussions also allows the researchers to communicate information as it was received, which furthermore acts as a form of auditing.

Variations in interpretation of transcripts can bring about questions of reliability. Bryman and Bell (2003) suggest that greater reliability can be gained by using different interpreters with different backgrounds, which is the case in this study. One researcher is from the 'in group' (Germany), while the other is from the 'out group' (Australia). A further way to minimize the 'unnecessary' explicit subjectivity in interpretation was to compare the findings for consistency in understanding.

In regard to objectivity, the researchers endeavoured to constantly be aware of how their values, attitudes and perceptions were influencing the entire research process, from the formation of the research questions, through the data collection stage, to the ways in which the data were analysed and theoretically explained. This research is not funded by any institution which reduces the degree of political impact. Authenticity will not be compromised since it is a university research and therefore less targeted to specific outcomes than most government or corporate research (Easterby-Smith, Thorpe and Lowe, 2003).

\subsubsection{Data collection}

Focus groups have considerable potential for research questions in which the processes through which meaning is jointly constructed is likely to be of particular interest (Bryman and Bell, 2003). However, problems concerning the 'group effect' (Bryman and Bell, 2003) could arise in such settings, for example an emerging group view may mean that a perfectly legitimate perspective held by just one individual may be suppressed. Discomfort between the participants is frequently a concern of researchers conducting focus groups. However, since this study did not focus on personal details of participants' lives, and all participants were students and furthermore acquainted with each other and the researchers, this apprehension should be reduced.

Another limitation to this study however is the use of a convenience sample. Ideally, the sample would have been more diverse in terms of demographics. The age of the participants was between 19 and 31, which does represent a population involved in making purchase decisions; however, it leaves out a significant consuming population above 31, which might have an entirely different opinion about origin cue and the EU. Furthermore, all participants were currently involved in 
acquiring a university degree. A French-Canadian participant pointed out this very particular setback, arguing that "right now you are asking 5 university students, if you go out to common people and ask them, you will probably get different answers". If the geographical groups which the participants were broken down to 'smaller' constructs, a greater homogeneity could have possibly been provided, emphasising different key themes. Another setback of this sample is that international students were asked, whereas a research on site could have resulted in different findings. The data collected from such a convenience sample will therefore not allow definite findings to be generated, due to the problem of generalization, however, Bryman and Bell (2003) suggest that this technique is useful for conducting development work on new measures or on research instruments, and can be usefully employed in relation to exploratory work from which new theoretical ideas might be generated. 


\section{THEMATIC FINDINGS}

The findings of this exploration into the working meanings attributed to a 'made in the EU' origin marking scheme, indicates that the meanings consumers attribute to such a labelling scheme are varied, experiential, situational and complex. This variation in meanings and the dependency of meaning on various factors largely reflects the socially constructed nature of meanings attribute to the construct 'the EU', and accordingly the construct 'made in the EU'. Yet, an analysis of the various meanings that constitute this construct are explored to attempt to gain a holistic (albeit inherently fragmentary) picture of the working meanings attributed to a supra-national origin label by the participants, which is apparent in the discussion.

The following chapter will disclose the findings of the research. The findings are organised into thematic patterns that illustrate how and what meanings are attributed to the supra-national origin label in question - 'made in the EU'. The meanings attributed to the EU as a construct appeared, to a significant extent, to be influenced by the participants' general knowledge of the EU. This proved to be noticeably modest and loosely mixed with the knowledge of, and the meanings attributed to, the geographical construct 'Europe', apparent through the interchangeability of the two terms 'Europe' and 'EU'. This confusion seemed to be amplified by the diversity of meanings attributed to the 'made in' label in general-'manufactured in', 'designed in' or 'assembled in'. The combination of such factors indicates some of the complexity involved in how supra-national origin labels are conceived by the situated consumers that participated in the research. The exemplary case of the EU illustrated that the general perceived diversity among the member states influences the overall equity of this origin mark, and associations connect to it. In addition to this, various variables appeared to influence the overall weight of the meanings attributed to the label, and accordingly the equity of the 'made in the EU' label; as equity is arguably directly related to consumers' meanings and valuation of such constructs. This again reiterates consumers' difficulty, situated complexity and variation in attributing meanings to such supra-national, stretched origins as the EU, and the consequent implications for their perceived value. These aspects are to be further examined throughout the findings.

\subsection{Theme 1 - The nature of the 'EU construct' and the meanings the participants attribute to this construct}

The EU, taken in this paper as a constructed entity, obtains implicit variation, alike many other conceptions of origins. Yet this 'implicit variation' and the consequent confusion it inspires appear to be amplified by the fact that the EU itself is conceived by consumers as clearly an 'infant construct'. That is, an infant construct with no solid and definite meaning, but rather as a social concept conceived by the participants as a largely fluid and hybrid construct. The perceived infancy of such a construct meant that the participants found it difficult to pin down meanings to such a construct and identify common meanings associated with it, compared to the more comfortable 'parent construct' Europe, and hence used the terms interchangeably throughout the discussions.

\section{The interchangeability of constructs - can the EU mean EUrope?}

Throughout the focus group discussions, the majority of the participants frequently used the terms 'Europe' and 'EU' interchangeably. Whilst the focus groups were directed at gaining information about the 'EU as a construct' (for the purpose of this research), responses frequently came back to 
stereotypes concerning 'Europe'. The interchangeable nature of these terms throughout this research is exemplified by the empirical findings. An illustrative example of this interchangeability is highlighted by this Australian girl's discourse- "the EU is France and Italy, Europe isn't Poland, but maybe Prague" (Sarah, 20 years old).

The respondents' interchangeability of the terms 'EU' and 'Europe' indicated that the EU is a new and unknown construct to consumers, which even citizens from its member states were not completely familiar and comfortable with. This hence had the implication of the participants often referring to the construct Europe, which to them appeared to be more informative and 'meaningful'. Participants particularly switched to the term 'Europe' in flowing, in-depth conversations. A French -Canadian participant reflexively noted that whilst even university students may not always differentiate between Europe and the EU, that 'more common people' would definitely not (Pierre, 22). He continued to comment that when his friends questioned him about his exchange abroad, questions would be directed to the familiar and common construct 'Europe', rather than specifically about Sweden or the EU. This commonality of the 'parent Europe' construct in everyday terminology is further exemplified by the Australian participant Toby (24), who argues that "you don't say that you are going to an EU country this summer, you say you are going to Europe or to a European country". A North American participant argued along similar lines about the use of the term 'Europe' in common everyday language, "Formally it is EU, casually it is Europe", he argued, "that's the difference between the two" (Charlie, 26).

Whilst most participants argued that it was acceptable to use these terms interchangeably, some argued against this. A member of the North American group argued that there is a difference between the constructs, and that should be noted with the terminology. For her the term 'Europe' is used to convey associations with the stronger predominantly Western European countries, whereas when she uses the term EU, because of the ongoing expansion and new Eastern member states, it is used to evoke the Eastern European countries, and that the other participants should be aware of these potential associations that are at least apparent for her (Shelley, 21, USA). Hence, it can be inferred that whilst the majority of participants understood the technical difference between the constructs, they did not feel it was so important in everyday terminology to distinguish.

The term Europe hence appeared to be used more commonly and unconsciously than the term EU (the supra-national construct), through a degree of familiarity and comfort with the precise 'meanings' of this term by participants. In some cases, this familiarity is clearly derived from Europe's strong historical background, heritage and accordingly stereotypes. Participants also appeared to find more common ground in discussions regarding this construct. Many of the participants were reflective of the fact that they look at Europe as a strong historical construct, with a strong heritage. This historical nature of the construct often appeared to be translated to contemporary attitudes towards the EU. A South African girl for example commented that it is hardly possible to divorce your experiences of Europe from your ideas about the EU, "Europe's impact on countries such as in Asia and Africa must be considered, Europeans have historically cheated us" (Mandisa, 25). A Kenyan participant argued contrary, that because of Europe's history and heritage, these terms should not be used interchangeably and cannot for him, because the EU, including its new member states, contrasts sharply to his 'childhood ideas about Europe'(Jahi, 31). For him the historicity of Europe could not be translated to the more contemporary politicized construct EU. Other members in this group concurred with this comment, such as Ade (25, South Africa), who remarked that, "The EU is clearly political, when you think about the construct Europe, it seems more of a natural geographical construct with a certain history, but the EU means something political, you also think about the countries that are being excluded for political reasons, but most of the time you just use the term Europe anyway". 
Thus, whilst many participants thought that the terms Europe and EU should not be used interchangeably when thinking about it reflexively, they acknowledged that they did it anyway. A Finnish participant argued that, as the EU's "Western logic is spreading throughout Europe and the Eastern states now, there is not much need to worry about the difference between them, I can't see there being any need later, at some point all Europe will be in the EU" (Lisa, 25). An Australian participant argued that he did not notice a difference between certain states that were not EU members, such as Switzerland, compared to similar states that were, "If I can't see any difference here, I guess I am not going to start being too careful about, when and how I use these terms" (Toby, 24).

It was also derived from the focus groups that participants, when using the term 'Europe', were frequently referring to the EU, yet when using the term 'EU', there was no indication that participants were referring to Europe. This reflects largely that Europe is the stronger and more familiar construct and also that there is lesser knowledge of the term 'EU', especially when it comes to pinning down the meaning of this complex notion. There was a general consensus especially among the North American participants that the EU was an 'infant construct'-'and maybe later it could develop and have a similar degree of prominence and strong associations similar to larger parent constructs such as Europe or the US'(Charlie, 26, USA).

\section{Knowledge of the EU construct}

Knowledge of the EU varied between participants and also their knowledge of the larger more notorious construct Europe. This affected their views concerning the construct EU and accordingly, if they relied on the construct Europe due to more knowledge and comfort with the term, to convey EU meanings. It was found that whilst geographical proximity largely influenced the meanings attributed to the construct 'EU' itself, meanings still varied immensely within geographically similar regions. Nowhere could a similar and precise image or construction be attributed to the construct, 'EU', by the participants. This indicated that the EU is not yet, unlike other origins, functioning as an imagined construct or regarded this way, by consumers 'inside and outside' this construct.

Geographical proximity, as mentioned, played a large role in governing participants' underlying knowledge of this construct. Yet, this confusion over meanings associated with the EU was illustrated by even participants from EU member states, with many participants admitting that they were not sure about which states were members, what the current activities of the EU were, or even entirely what the Union was intended to mean or achieve. Despite the confusion, some EU group members still identified with this construct- "I feel that I am part of the EU, I am European, but specifically Finnish", Lisa (25) remarked and Pablo, a Spanish man (26) argued, that as he was from Catalonia, he identified more with the EU and its values than with Spain.

Confusion appeared to be amplified the further the participants' geographical proximity to the construct in question. The Asia/Pacific group, when discussing their opinion of the EU, often referred to the Romanian people. The fact that Romania is not even an EU member reflects this superficiality of knowledge. Sarah (20), an Australian participant, stated that "the EU is clearly a geographical construct, in primary school you learn the continents, 'that's Europe', everyone is the same in Europe, in Australia they're all Australians and in Africa, they're all Africans". Often, Sarah also referred to the behavior of her classmates at high school, who, unlike her, had not been to Europe and who had mostly limited knowledge of the construct- "People at school would say 'oh this is from Europe', even though they had never been, they would say it to show how classy they were." That is, they appeared to rely on stereotypes to convey meaning and discuss the construct, which appears to be a product of their limited knowledge. 
Participants appeared to be able to stereotype more easily the constructs EU and Europe, depending on the further away their geographical proximity was from Europe. This seemed to be in some cases a product of 'cultural norms' or a lack of knowledge. Often stereotypes were experientially or historically contingent. Mandisa (25) from South Africa, commented that her vision of Europe was based on historical experiences with the continent- "they colonized us and that makes me think of the most powerful countries to be associated with Europe", she acknowledges though, that these views are not necessarily current, but any other image she has is also shallow- "like, if a person is wearing white shoes in Africa, oh you think they must come from Europe, I guess that is also shallow, right?" Another member of this group, Ade (25, South Africa), argued that the majority of information on countries or regions are stereotypes- "I mean, they have to be, everyone is so different in each place", he argues that the easiest way to stereotype is often based on display, "it's superficial, but it is the only way".

Such stereotypes were common throughout the groups, they were ultimately display-based, except these 'display-oriented' stereotypes, evoked by different participants, varied depending on their 'situatedness'. Many stereotypes or images described by members of the various groups were commonly 'laughed at', indicating a mutual understanding and cultural agreement on the stereotypes. For example, Sarah (20, Australia) argued that for her, Europe conjured up images of "intellectuals sitting around in cafés and drinking coffee". The focus groups all tended to indicate a general lack of knowledge concerning this construct and accordingly different images and ideas. Associating the EU with either the new Eastern members versus the 'old Western members' was another popular image, reiterating the infancy of the EU construct. Hence it can be understood that in comparison to Europe, which the participants identified as the more comfortable and familiar parent construct, in which they could easily locate meaning and hence discuss it, the EU is a new and infant construct, which the participants have limited knowledge about. Even the EU members who identified themselves as European or as an EU member, part of the 'in group', seemed to have limited knowledge of this construct. This also has the implication that - to the participants currently, the EU means too many diverse things and it lacks a solid concrete meaning, to be a meaningful and comprehensible origin. 


\subsection{Theme 2 - Origin marking schemes - the 'made in' label}

\section{Globalisation and complexity}

The groups indicated some confusion about the 'made in' origin label itself as a construct, which is exemplified in the following participants' arguments. Possibly, this confusion is a product of globalisation and its associated processes, as Jahi (31, Kenya) argued, "a lot of the time you don't know what you're getting, the term 'made in' is too general, then you are forced to rely on geographical reputations, it is just too difficult to trust". Lida's (23, Czech Republic) comment also supported this claim, "Now many products are made everywhere, say like cars, I know that, and because of this I don't think a label says that much anymore". Ade (25, South Africa) on a similar line of thought claimed, "yeah, now cheap labour makes sense with globalisation, I consider the 'made in' label to be associated with globalisation, I trust the brand to give me the standard, I don't think many people trust origin labels anymore." Mandisa (25, South Africa) responded to this comment- "Globalisation and the 'made in' label doesn't really matter anymore, people are just so sceptical now, you just are pretty much forced now to trust the brand- I mean unless you make a conscious effort to be like a 'green shopper', or 'origin shopper', I think with globalisation now, people just accept that things are made everywhere, or they are unconscious of it, or they really just don't care." Fang (22, China) argued that "even when they do show the label it doesn't really give you much information anyway".

\section{'Made in' as 'manufactured in?'}

Participants throughout the focus groups took the actual 'made in' origin marking scheme to mean many different things. Several of the participants believed that the 'made in' label had a direct connection to manufacturing connotations, which is illustrated by Danny (20, Canada), who connected trusting and adequate labour conditions with a "made in the EU' label, "at least you know that with an EU label it is not going to be produced with slave or sweatshop labour." Mitchell (26, Canada) in this group counter-replied- "even if it is going to say it is "made in the EU' most of the time it will be manufactured in other places, what we really are talking about is the same products which are just being marked up". Charlie (26, USA) attributes two different meanings of the 'made in' label in his reasoning- "I don't look at the 'made in' cause I really don't care about the manufacturing place anyway, I am just more concerned with who overseas it". He added that "basically all that a 'made in' label, for example a 'made in the USA' label, indicates is that there's a team of accountants positioned somewhere in the USA". The Asia/Pacific group though had a strong manufacturing-based understanding of the 'made in' label, along with the African and the EU focus groups. Fang (China) commented that to her, these labels are seen in terms of costs, attributing the country label to the production costs- "I wouldn't think that something, like a car, was specifically safer if it was 'made in the EU', I would just think that it cost more to produce". Andrew (20, New Zealand) commented that you cannot really know where it is produced anyway, "With 'made in the EU', I think it would probably be produced somewhere like on the border to the Middle East".

Hence it is apparent that to participants the 'made in' cue has been confused and complicated by globalisation and its consequent processes and trends. 'Made in' today evoked various meanings and associations to the participants, there is no conceivable standardisation associated with any origin marking scheme to the participants, especially supra-national origin marking schemes.

\section{Nationalism and Globalisation- The circumstantial equity of a 'made in' label}

For some participants, globalisation and its impacts have resulted in a degree of nationalism, which is reflected through consumers' reflexivity of 'made in' labelling. Mandisa (25, South 
Africa) commented that if a 'made in' label showed that, for example food was coming from Europe, she would refrain from buying it- "The EU government gives money to the European farmers and our farmers are struggling, as a consumer today you must consider many things now, I just see this as a political and an economic solution to something". Ade (25, South Africa) concurred, that at home they had many campaigns to encourage such nationalism, as was explained by some Australian informants to be the same case in their home country. Danny, (20, Canada) argued that any such 'buy Canadian' campaign, concerning the purchasing of homegrown products, now pretty much only affects his parents' generation. Compared to these nationalistic tendencies, Fang (22, China) argued that the majority of Chinese consumers felt differently, and that a 'made in China' label was often a deterrent to purchasing behaviour regarding certain products. Fang continued that purchasing Chinese products was even seen as embarrassing, she remarked, "I come from China, I don't want anything made in China." Kurt (19, UK) argued that with globalisation it is almost impossible to be nationalistic anymore, "in Europe it is not really possible to buy home-grown".

In terms of nationalism, in a less explicit sense, most participants argued that they trust the standard of products, which are let into their countries and their national regulations in place, and that hence, there is no need to actively check or care so rigorously about 'made in' labels. However, Shelley (22, USA) stated that in certain climates she does make use of the origin labelling, such as on her recent trip to Russia, were she frequently checked such labels as she did not trust the products that were let into that country.

The research findings have indicated that 'made in' has been defined as the country where products were 'assembled', 'built', 'manufactured', 'engineered', or 'designed', as well as the country 'where the brand originally comes from' or 'where the headquarters are located'. This confusion can be ascribed to the increasing prevalence of hybrid products which typically have more than one country of origin, since they are often designed in one country and manufactured or assembled in another. Hence it is increasingly becoming difficult for consumers to extract the range of definitions hidden in the term 'country of origin', which could lead to the assumption that the origin effect shifted from the product to the brand, which causes consumers to increasingly rely on brands for information.

\subsection{Theme 3 - 'Made in the EU' as an exemplary supra-national origin marking scheme}

The variations and ultimately limited knowledge implicit in the participants' constructions of the terms Europe and the EU, made it accordingly difficult to discuss meanings associated with a hypothetical supra-national origin scheme 'made in the EU'. Discussions concerning this potential scheme consequently stimulated a variation of responses regarding this construct, its associations and images. The meanings discussed also revealed the situatedness of various comments, which at times appeared to be a product of regional background, in or out group status and various experiential meanings that were located at the individual level.

\section{Variation within the label}

Respondents argued that the term EU, (or if they used the term Europe despite this) was too diverse to mean something concrete, except at a stereotypical level. There was a general consensus that the variance among the EU citizens and the various environments of the EU was too diverse to mean something concrete to the participants. This view is illustrated by Mandisa's (25, South Africa) comment, that the idea of a 'made in the EU' umbrella label can be seen as a "dilution of these peoples' identities", as a "political and economic idea that has nothing to do with the 
people"- "while these politicians probably see this EU-label representative of their perfect utopia , the fact is that it is just confusing, the EU is made up of too many states, with ideas about who they are and about who other people are, there are just too many values together, the only common value I can see is expansion." Habibu (28, Ethiopia) argued in accordance with this- "when I look at the 'made in' label, I guess I am sometimes thinking about things such as 'technical knowhow', I don't know if I can do this with the EU, the variance is just too broad from country to country..., I guess though that my initial reaction is that it is from Europe, so it can't be too bad, but the more I think about it, it really is just too difficult to generalise". Similarly, Jahi (31, Kenya) argues that "some countries in Europe have experience and know-how in some product categories, you feel better buying those. But even if it says EU label, there are some countries that are known to not make like for example good shirts, so you don't know what country it is from, it might make you reconsider the purchase."

In acknowledgement of the variation implicit within the 'made in the EU' label, the participants suggested that there needs to be some common ground for the basis of evaluation Danny (20, Canada) commented that the quality will need to reach certain requirements, "there would need to be some regulation of the quality within the EU, so there will be some common standards, it is too early for the EU to have a reputation and it would need this if I am supposed to trust it, like you can't compare the EU yet to a trusted place like, for example Canada or the US, at least not yet". Toby (24, Australia) argues similarly, saying that "an EU label will have to have consistent quality, good and bad shoes with the same label, that's gonna ruin everything".

The underlying idea of these conversations implied that the variation in quality needs to be addressed, for such a supra-national origin marking scheme to be meaningful and viable from a consumer perspective.

\section{The equity of the 'made in the EU' label}

Many of the EU members concurred, that when discussing influences on their buying behaviour outside their specific 'region of trust', the 'made in' label increases in importance. This is indicated by the frequent statement that, if all other cues were the same, they would rather buy 'made in the EU', often if even all other cues were not the same. It was also argued for certain product categories that respondents would even pay more for a specific 'made in' label, Pablo (26, Spain) indicated that, "I would definitely pay more when it comes to certain things, such as food". Mandisa (25, South Africa) indicated along similar lines, that there is a certain equity and status with this EU label-“If I'm rich I'm going to Europe, If I'm poor I go to Japan". Toby (24, Australia), new to Sweden, saw Europe or the EU as a more valuable homogenous construct, along with products that carried a label that evoked this. Brands such as 'Euroshopper' that have an implied European origin were seen as a 'safe label', "Initially when I came to Sweden I trusted it, I couldn't read the labels, but 'Euroshopper' products are also in English, it looked ok." Andrew (20, New Zealand) argued that for him, such a label could never imply something truly homogenous, "a label like 'Euroshopper' implies that something is being covered up, for me it is an unknown brand which doesn't really mean much". Toby (24, Australia) responded that he just really did not care that much, for him at least the product is 'made in the EU', "that's good enough for me". Furthermore, it was argued that a 'made in the EU' label could even provide some consistency for a company, as suggested by Sarah (20, Australia), who argues that for companies with an accountable brand like H\&M and Ikea, that produce goods in many places, "rather than having some labels like from Turkey and some from say Hungary, an EU label could provide companies with some consistency and that could be a good thing." 
Even the EU group argued that they would put a certain degree of trust in products labelled 'made in the EU', and would prefer those over 'outside and foreign' products, such as those 'made in China'. Kurt (19, UK) argued, that with certain nationalistic products, like for example British beef, a lot of people would be upset if it had a generic EU label. But quality wise, replacing the national label with an EU one does not really matter, since it is not the 'made in' label that reduces risk, "but through the fact it is able to be sold here". Francesca (20, Italy) complements this argument, saying that whilst the 'made in' label possibly dilutes a country's excellence in a particular field, the label itself is actually 'not too bad', "a 'made in the EU' label, for me, despite the many countries in the EU, it does reflect a certain standard, and reduces a lot of the risk".

This attitude was contrary to many of the researchers' nationalistic 'working hypotheses' of this group; that many members of the EU group argued that if a product was labelled 'made in the EU' they would not care, since they do not care too much about the actual country labels in the first place. A lot of the participants within this group and the other groups (except predominantly the majority of the Africans and the Chinese) argued, the fact that a product is allowed to be sold in their country encourages trust in it. This has the implication that consumers do care, more so, about the 'made in' label if they are in a situation where they cannot rely or trust their own specific 'regional origins' or authorities, which was also suggested in Shelley's previous comment about standards in Russia.

\section{Associations with the 'made in the EU' label}

Despite the variation implicit in such a construct, from a consumer perspective, such a label still did evoke certain associations, yet these images conjured varied which accordingly impacts the label's equity. To Jahi (31, Kenya), the 'made in the EU' label evoked an extremely vivid image of a colonial empire, as a living organ and a colonial power, whereas to Mandisa (25, South Africa) it evoked an image of a "mixture of Jacques Chirac and Margaret Thatcher". For Fang (22, China), the label 'made in the EU' evoked "something that you could buy at the airport".

Many of the images evoked from the participants carried clear attitudes associating the label with either a positive or a negative overtone, usually dependant on whether they associated the construct predominantly with Western or Eastern Europe. Charlie (26, USA) clearly saw such a label as a blatant marketing strategy to level the playing field between Eastern and Western Europe:

“On the one hand, if you were to put 'made in France' or 'made in Italy', I would see that as a luxury mark, to put in like 'made in' some sort of Central or Easter European Country, I would see that as 'oh, it's gonna be cheap'. So, to me, to kind of lump those two together, all together creates something where I don't know what the meaning is. Like, could be luxury, it could be cheap, it could be expensive, it could be inexpensive, I don't know what it says, I don't know what it's telling me at all." Danny (20, Canada) conversely argued that " $(\ldots)$ despite all those different countries and places that the stuff could be from, I'd say that as soon as you say all other things the same, having an EU label is better than not having it." Charlie counter argues: "I wouldn't be so sure, cause if I don't see anything behind 'made in EU', I mean, if I can't tell if this means East or West for me the label loses a lot of its prestigious value, I really think it is gonna make Europe less competitive."

In the Asia/Pacific group, Fang (22, China) in accordance with this line of thinking argued that she would definitely see the Eastern European countries behind such a 'made in the EU' construct. "I think it is because, like for different countries, they have their advantage, like France is famous for wine, Germany is famous for cars, (...), and if it is labelled by like EU, like if a car says made in 
EU, 'made in the EU' has no competitive advantage, it is a negative thing, there is no advantage for the car company to compete with other countries. (...) For some countries maybe Romania, or the Czech Republic, if they don't have a competitive advantage for their products, then maybe they rather think, oh, it's a good idea, maybe EU can cover some bad things, but for Germany, they might think 'we have a strong reputation for our car, and if it says made in EU, our reputation is gone, covered by this stupid label. So if companies can choose, then the Eastern European Countries will use this label, cause it can give them more symbolic meaning."

She continues to argue though maybe, in China generally such a label may not carry this meaning specifically, "In China a lot of people don't care as long as it is not manufactured in China, they would think the product was more expensive if it comes from Europe, I don't think they will care if it says "made in EU'". Sarah (20, Australia) from the same group argued, "For me it is really the fact that they don't say the country, that makes it sound a bit dodgy". All members of the African group also agreed that this construct for them was associated with the negative Eastern European countries, while the EU group predominantly associated the label with the stronger Western European countries.

Hence, 'made in the EU' is evaluated as a truly multifaceted construct by the participants. Despite whether they were located within the EU or outside, the participants tended to locate meaning differently (that is across and within groups), the major implication being that the EU construct is currently too infant to mean something tangible to them. Their perceived variation of people and environments of the EU member states also contributed to this uncertainty of meaning and consequently the images evoked, implying that currently the EU is something that is commonly imagined. The variation in responses and associations also implied that such a labelling scheme could not possibly work or be commercially viable until consumers could pin down 'similar' and common meanings, values and associations with such a construct.

\subsection{Theme 4 - Variables influencing the meanings and equity ascribed to the 'made in}

\section{the EU' label}

The meanings attributed to the 'made in the EU' label varied in significance among the participants. This was seen to be due to other variables than 'origin' influencing a hypothetical purchase intention. Origin was reflexively noted to not be the only cue that consumers consider, but the origin cue's meaning and relevance shifted depending on other product aspects, category considerations and market forces. Such product matrixes therefore impacted the meaning and their weight ascribed to the 'made in the EU' label. Product category, high or low involvement products, the existence of brands, stereotypes connecting product to a nation's image, as well as the origin of competitors' products were seen to have an impact, not in the way of what meanings were attributed, but rather in the way as of how significant they were considered to be. This shows that the origin cue itself is highly situational and its relevance is dependant on many other factors.

\section{Product category}

The group discussion and exercise findings indicated that the significance of an EU origin mark is dependent on the product category. Kurt $(19, \mathrm{UK})$ states that "with food, to a degree more than I thought, the country of origin affects my purchase decision". In relation to the "made in the EU' mark, Pablo (26, Spain) argued that "I'd pay more for food if it had an EU label". Pierre (22, French-Canada) argued similarly, saying that "depending on different kind of goods, you search different information". It was furthermore argued that product categories in which the EU is 
'known' to make quality products (often by stereotypes), are more suitable to a 'made in the EU' label, such as Shelley's (22, USA) comment "apparel and accessories in general would benefit from a 'made in the EU' label, cause you associate Europe with style". Habibu (25, Ethiopia) argued similarly about the relevance of product category on evaluations of the origin cue. He said that "if it's a product category where there is a big difference between EU and my home country regarding the quality and regulations, such as with medicine, the EU label will have an impact when I purchase those products".

\section{Involvement}

Another element which was indicated to impact the relevance of the EU label was the products' involvement. Mandisa (25, South Africa) commented that "You want to make sure where it comes from when you spend a lot of money" indicating that she sees the country of origin as a "quality approval' with high involvement products. Sarah (20, Australia) argues similarly, stating that "the importance of the label depends on the price, if there is more money involved, I want to know where it's from, I want to know it is good quality". Correspondingly, some other participants' arguments indicate little interest where low involvement products come from. Danny (20, Canada) argued "I really don't think much when I buy soap", or Charlie from the same group who claims that an EU label on juice will not influence his purchase, since he looks at the price. Illustrative for the suitability of an EU label relative to perceived product involvement is Toby's (24, Australia) comment-"If you buy a soft drink, it does not matter if it says EU, Italy or France, but if you buy a leather couch, if it says EU or Italy, that makes a difference". He continues arguing that "maybe it is just the luxury products where you want the single country; maybe it would not make much of a difference for products below the high quality goods, cause there is probably not too much of a quality difference across the member states".

\section{Product - country stereotypes}

The focus group discussions indicated that products are frequently associated with specific countries or regions, mainly because of stereotypes. Charlie (26, USA) argued, that "You have a preconceived notion of what countries produce what quality goods, and that influences of course what products you think are good". Fang (22, China) uses these country stereotypes when she argued that "I don't want an EU TV, cause the EU is not known to make good TVs, I'd trust an Asian brand more".

Some participants argued that with products which are too closely associated with a specific country, a 'made in the EU' label might 'dilute the country's excellence in this specific field', since the EU is too much of an 'infant construct' to have specific product stereotypes. Shelley (22, USA) argued that specialised goods are usually unbranded and therefore more associated with a country- "specialised goods usually come with a specific country, like Wine and France". Lida (24, Czech Republic) argues that when buying coffee or wine, for her, the origin is of particular importance- "when you buy those products, you usually don't know special brands, so you buy a country where it is made, so a 'made in the EU' would hurt, because it does not tell me where it is made". Similarly, Sarah (20, Australia) argues that for wine, in her view, an EU label is negative, because there is too much variation throughout Europe to give wine a generic origin-label- "with stuff that is so closely connected with a location, I just want to see the individual country or region on it, like South Australian wine; but for wine there is not one consistency throughout Europe, some wines are really good, like from France or Spain, but what about a Polish wine, it's not famous for making good wine,'. Mitchell (26, Canada) argued similarly, saying that he would not purchase, for example coffee with a 'made in the EU' label- "coffee and all those coffee machines are too closely connected to Italy, who would want to buy EU coffee, and what about Spanish 
ham, is it going to be EU ham?". Lisa (25, Finland) further argues that if there is a productcountry connection, the 'made in the EU' label would "kill the product, especially when there is country value in products".

Hence, it is apparent that an EU origin mark is not seen as suitable for products that rely less on building their brand, and more on certain traditional country values and associations.

\section{"Depends on what you compare it to"}

'Depends on what' was a similar theme that emerged throughout the focus groups, that 'made in the EU' gains or loses equity depending on what you compare it to, as outlined by the factors above (product category, involvement and product-country stereotypes). The idea of 'depends on what' not only reflects participants' idea of inherent variation within the EU, but also from factors outside. Mandisa (25, South Africa) argued that if there were good products made at home, she would prefer those over 'made in the EU'. From the same group, Habibu (28, Ethiopia) argued that, compared to 'made in China' he would prefer the 'made in the EU' label. Lisa (25) from Finland used a similar example comparing her preference of 'made in Finland' over 'made in the EU', but 'made in the EU' over 'made in China'. Many participants in the EU group coincided that compared to anything outside the EU, they prefer the 'made in the EU' label and in certain circumstances would pay more for it. Another emergent theme among the North Americans was that if all other cues were constant they would prefer the 'made in the EU' label, yet in reality a single-cue purchase decision is rarely the case.

\section{Brands as the supra- valuation cue?}

Brand and company names on products seemed to have a major effect in purchase intent, making any kind of origin label less influential. The following comments by participants throughout all focus groups illustrate that brands are seen as accountable for quality standards more so than the country of origin. Mitchell (26, Canada) argues that "we totally rely on companies and brands for quality", "brands give the warranty and a quality standard, who cares where it is manufactured' (Ade, 25, South Africa), "I'm going for a famous brand, I don't care where it comes from", or "you want Sony, no matter where it is from" (Fang, 22, China). Whilst most participants agreed on the importance of brands, there were some discrepancies in the African and Asia/Pacific group on the superiority of brand names over country of origin cue, as outlined in the following dialogue-

Ade (25, South Africa): "You know, I would like to raise another thing, very important thing, it is also dependent on the brand, I mean like, take as an example Nike, you know, I don't know where originally they are doing Nike, but Bangladesh also produces Nike, they manufacture there. Most of the people, when they buy, they don't check whether it was made in Bangladesh or it was made where Nike originated, you see, now we just buy Nike, when we check the label, it is like, 'Oh, made in Bangladesh', but hey, there is still the same product, it doesn't matter if it's made in Bangladesh, you know, maybe you are surprised, 'Oh, made in Bangladesh', but even if it is made in Bangladesh, like, the standard's the same, it is a different product, but the quality standard is the same cause it's the same brand, the selling power is the brand."

Habibu (28, Ethiopia): "Okay, yeah, but then look at another thing, for example, South Africa, you guys are making Toyota Prado, but they are not good, and people are more preferring Toyota from Japan. In my country, Prado, the brand is good, but, they are cheaper, than Japanese Prado. I'm telling you, what people are complaining is that the Prado, not the Japanese one, the one from Africa ,it is getting old very fast, and after two years you can have so many problems. People would rather want the Japanese Prado, I do not want a Prado from Africa, they're not good." 
Similar conflicting arguments occurred in the Asia/Pacific focus group-

Fang (23, China): "At home, when we went to the sneaker store, and buy like Nike shoes, the first thing people check, it's not the price, it is: 'made in where?', 'which country?', and if it like says 'made in China' oh, I won't buy it, because I know it is cheap. But like if it is saying 'made in the US', oh yeah, maybe I should buy it, cause it is not made in China. But I come from China, I don't want something made in China. It is embarrassing, I don't know, in China, it is embarrassing, like if you wear a Gucci Jacket, and suddenly your friends see, oh, Gucci Jacket, made in Malaysia, that would be a horror thing."

Sarah, (20, Australia): "Oh, if I would buy Gucci, I really don't care, I would probably think, I buy Gucci, to me that is Italian."

Fang (23, China): "Someone earlier mentioned BMW, it's like also manufactured in China, so, it is made in China, so the price will also be low, because of the costs, you know, and then now we have a quite sensitive debate about that, people don't want a Chinese BMW; and they want like pay more money to buy a German BMW. I guess they think maybe that if the BMW is German, or made in Germany, or in Europe it will be better than the Chinese one."

Hence, in most cases, the brand appeared to be a more influential cue than the country of origin cue, reducing its importance. In terms of the EU origin mark, it was argued that strong brands will not be 'diluted' by a 'made in the EU' label, for example Shelley (22, USA) who argues that "with most products a 'made in the EU' label does not matter, cause it is more a brand thing", or Fang (23, China) who argues "I want a Sony, no matter where it is from". Almost all participants appeared to rely on brands to convey certain information about product quality or attributes. This is possibly as a consequence of the participant's confusion of the meaning of 'made in' labels, as discussed earlier.

This relevance of notions such as 'country of origin' information and cues, as the findings indicate, suggests that it is being superseded by brands. Brands are increasingly more tangible to consumers and considered less confusing constructs; this has arguably been the result of current trends and forces such as globalisation. The findings reveal that such trends have not only diminished the role of country of origin as an information source, but supplanted it by the idea that country of origin is rather a misinformation source, there no longer exists a concrete meaning for the 'made in label', despite when it is lumped together with another unfamiliar construct to consumers.

The findings indicate that the reason that brands appear to have become the dominant cue in decision making, rather than other traditional cues such as country of origin, or other labelling schemes. Brands appear from the findings to have taken a lead role in informing the consumer about product attributes and standards. The participants not only appeared trust the brand construct more, but perceived the brand construct to reveal more information about 'country of origin' than any explicit origin marking scheme, such as a 'made in' label, at any level. When unfamiliar constructs such as 'made in the EU' were presented to consumers, the shifted trust to the brand appeared to be amplified further.

These findings raise certain implications about the viability, of not only the proposed viability to consumers of supra-national origin marks, but origin marks in general and their representation in the public sphere. 


\section{DISCUSSION}

This exploratory research project has indicated that the meanings which are attributed to a 'made in the EU' labelling scheme are varied, complex, situational and confused. The variations, themes, similarities and differences concerning this supra-national origin construct suggest, that these meanings go beyond consumers' systems of understanding, constructions, images and associations, due to the infancy of this construct and its lack of a 'perceived origin' and heritage. Other varied hybrid social constructions, like multi-national brands, are 'manufacturing' a sense of heritage, which origin marking schemes are currently not doing. Brands are increasingly manufacturing such heritage in an attempt to provide a sense of stability and meaning to consumers in this age of fragmentation of 'origin'. This primarily operates at the supra-national and global level, despite whether or not it is labelled so explicitly. These following three constructs, as outlined below, are elaborated on, as these were primarily found to influence the meaning process and the consequent viability of supra-national origin labels.

\subsection{Infancy of this construct}

The interchangeability of the terms Europe and the EU, and the apparent lack of knowledge reflected the infancy of this construct- 'the EU', resulting in a cacophony of meanings attributed to this supra-national construct, (compared to the more familiar concept of Europe). The explicit use of the term 'Europe' throughout the research indicated, that not only is this term more comfortable to consumers, but arguably it is a product of the lack of knowledge regarding the EU construct, which makes it understandable that the participants found it difficult to differentiate between the construct, Europe and the EU. The combination of this 'infancy' and lack of knowledge amplified the perceived variation within this construct. The infancy of this construct to the participants, is not only reflected by the short existence of the Union ${ }^{7}$, but how tangible, visible and relevant it was perceived to be in their lives. O'Shaughnessy and O'Shaughnessy (2000, p. 58) claim that for a place to be perceived as an origin, it needs to convey a range of concrete meanings, the "debris of history and contemporary".

The infancy of this construct has the implication that the EU cannot overwrite the participants' perceived variation among the member states. If it wishes to place a 'generic' supranational umbrella labelling scheme, it must overcome this. Thus, the EU arguably needs a strong manufactured history and heritage, which is not only tangible and relevant to consumers, but means something concrete to them.

\subsection{Lack of heritage}

As mentioned, the EU's lack of heritage is associated with the fact that the EU is perceived as an 'infant construct'. Arguably, for a social construct such as an origin, to be actively imagined by consumers it has to be the product of a lengthy symbolic process of social construction and meaning negotiation. Accordingly, the consumers' view of an origin arguably must be a composite of beliefs based on experiences and emanate from the imagery of its people. Thus, it is

\footnotetext{
${ }^{7}$ The initial creation of the European Union began after World War II (it was first called the European Community). The Maastricht Treaty on the European Union took effect on 1 November 1993. The term 'European Union' is actually used to describe the wider Maastricht framework in which all these activities - old and new - take place (Littler and Schlieper, 1995).
} 
a fantastic idea that Europe's heritage could translate to the EU, yet this is not a reality, as inferred from the participants- that is Europe can mean the EU, but the EU cannot mean Europe. The EU has to manufacture its own distinct heritage and communicate it values and equity to consumers, of which Europe can be a part, but not an entire entity. Such a heritage can only be manufactured through the creation of certain values and common associations.

The idea of origin stretching and the importance of heritage relates to a pertinent point in terms of how consumers arrive at knowledge. The social constructionist stand point taken in this research assumes the position that knowledge and meanings are derived from other systems of knowledge and meanings. That is the creation of meaning is a process that does not stand alone, but is highly interdependent to other meanings, created by these meanings and built upon. When an origin is stretched to a supra-national level, there are various implications in terms of the systems of meanings required to produce new meanings, for example consumers cannot just imagine an EU community, an EU origin or an EU label, it needs to be built on other systems of meanings, this is part of its heritage, it cannot be in an 'infant state'.

This may mean that to achieve the desired goals of the commission, by placing such a 'made in the EU' label on the products, greater knowledge and some 'social agreement' would have to be achieved regarding such a labelling scheme and this is, as mentioned, highly dependant on other systems of meaning, conveyed primarily by heritage. Other potential sources of meaning required for a 'made in the EU' labelling scheme to become a viable construction and meaningful to consumers would be information concerning what a trade bloc is, what type of agreement the EU is, and what its 'consistent' values and plans are.

Therefore, arguably, putting such a 'made in' origin scheme on products from supra-nations would benefit only from the construct having a pre-existing heritage. The enforcement of certain standards on such a scheme could eliminate consumer's confusion and variations in meanings, it could also alleviate some of the apparent confusion that is a clear product of globalisation, such as what 'made in' really means in our contemporary consumer society. If certain standards and values were enforced with the labelling scheme, it could simultaneously help to create an EU heritage or establish the EU as an origin.

\subsection{Lack of perceived origin}

\section{Consumers' perspectives of the EU as a hypothetical supra-national origin}

Currently the findings indicate that the participants see the EU as a 'quasi-origin', something where products could come from but also could not, somewhere 'in-between'. Currently the EU appears to not be viewed collectively (in any sense), or even individually, as a 'fixed location' where things can come from. It appears to be far away from being conceived as an 'origin' in the sense that a country or micro region is, despite whether or not this is now a more realistic label for products. The nature of the EU, or trade blocs in general, for that matter is structurally extremely different from these traditional conception of an origin for consumers, it is a product of globalisation and accordingly needs new techniques for its 'active imagining'.

Without certain concrete meanings attached to them, even 'quasi-origins' can become stereotyped negatively or positively. Yet, the most plausible path would be that products are stereotyped negatively. This is already revealed with the majority of respondents indicating that they associate 'made in the EU' with the negative, cheap and Eastern associations. There is a clear trend that consumers are becoming cynical through misinformation, part of the 'consumer confusion' associated with globalisation. Whilst the European Commission states that such a project is directed at providing consumers with more information, it is not necessarily seen this way by 
consumers, as indicated by the confusing nature of this 'construct' currently. It would also be extremely damaging if all the products under this scheme were not at the same standard. This point relates back to the fact that the countries in the EU are not at the same standard, or perceived to be so by consumers. There are huge divides and variations between some of the member states which can make it difficult for a common image to eventuate in the consumer psyche, that is as the EU as an origin. The EU would not only have to build values and strong associations to influence consumers to make positive associations with the EU as a construct in itself (to overcome many of the predominantly negative associations with the EU), but also to facilitate the building up of the EU to an 'origin' rather than a varying, floating 'construct'.

Arguably for an origin to be strong and exist in the consumer psyche, it must have clear human and environmental 'common' associations, in which currently the EU possesses none of these criteria. This does not rule out in the future that it could not, but at this point in time the participants did not view it in such a way. To do this, it needs to manufacture a strong sense of heritage and an associated social concept which is meaningful to consumers (see figure 2).

\section{Figure 2}

The interplay and role of the origin's social concept and heritage

$\begin{array}{lll}\text { Micro-region } \quad \text { Country } & \text { Macro-region } & \text { Trade blocs }\end{array}$

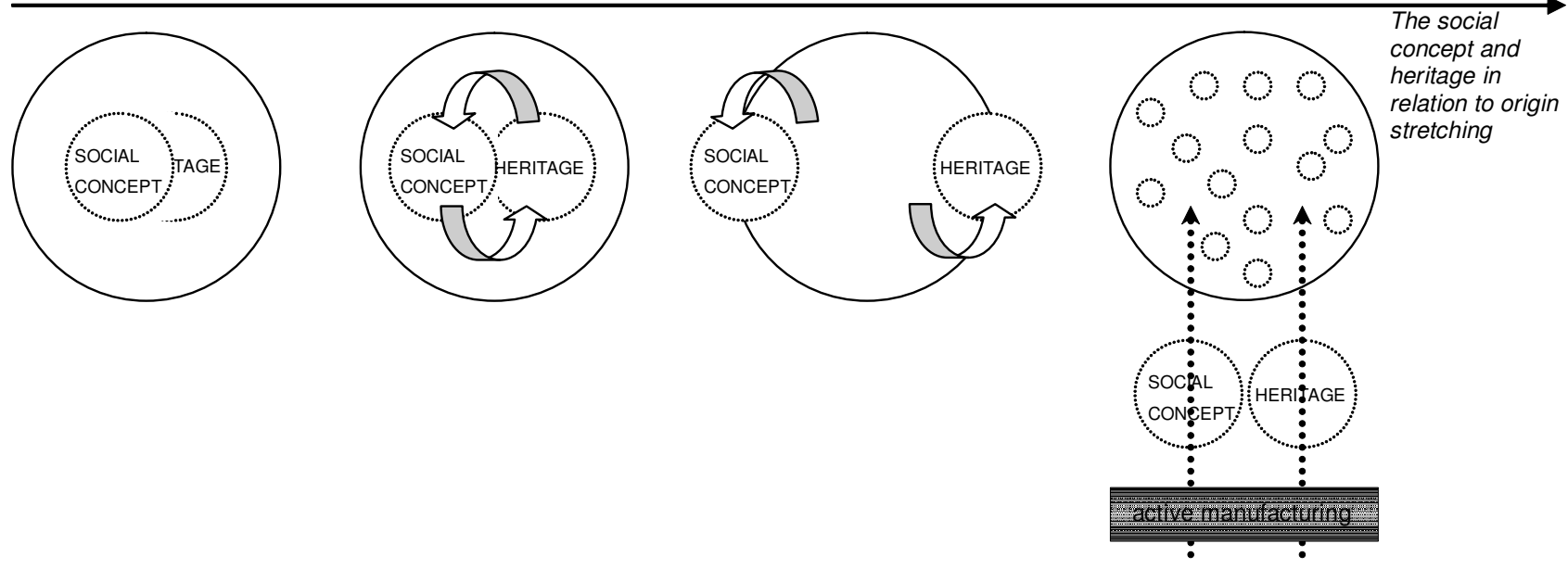

Figure 2 shows the interplay and role of an origin's heritage and social concept as it stretches through various levels. At the micro-level, heritage and the social concept interact closely, facilitating vivid associations from the consumer. At the country level, the interplay separates and becomes less naturally associated. Despite this, there are some tangible associations recognized by consumers through their ability to stereotype. At the macro-level, the social concept and heritage are apparently no longer naturally connected in consumers' associations. This is due to the implicit variation in regions at the macro-level, yet history provides a vague concept of heritage and a social concept, such as historical ideas about Europe. At the trade bloc level, there is no strong social concept or heritage due the infancy of the construct and the even greater perceived variation. There appear to be just various personalised 'quasi-opinions' which do not evoke any particularly strong or common associations. Therefore, alike brands, these needs to be actively manufactured.

\section{Meanings attached to supra-national level 'stretched' origins and the implication of this 'stretching'}

The concept of variation is one of the main points which can make it extremely difficult for the EU to be conceived as an origin, or hypothetically other supra-national origins. The Commission's 
plight to 'brand' the EU to consumers and for consumers with such an origin scheme initially entails it to be seen as an origin in which things can come from. The study has revealed that when the concept of origin stretches to a larger and varied construct, it can become extremely difficult for consumers to envisage, associate with and attribute meanings to. The study reveals that when 'origins stretch', consumers' ability to stereotype and use the origin cue as a useful evaluation tool becomes significantly reduced. Such variation and confusion necessitates a manufactured heritage to attribute meanings and negotiations to such supra-national constructs.

\section{Origin stretching as influenced by how consumers arrive at meaning - and consequently the need for heritage}

The project of introducing a supra-national origin marking scheme may furthermore prove to be increasingly difficult as the findings indicated that consumers are becoming increasingly weary with such labelling schemes and the viability of the 'origin cue', in today's age of globalisation and its associated processes. Coupled with this, the ability for consumers to accept the new construction 'made in the EU' is increasingly difficult. As discussed earlier, for many of the participants inside and out, the EU appears to be too foreign of a concept, without any tangible relevance in their lives. As more familiar origin cues are declining in importance to consumers, it is difficult to envisage the successful branding of trade blocs, especially if consumers don not perceive them as having any tangible or direct relevance in their lives.

An important implication of this study is that consumers have shifted their trust to the brand and its 'perceived origin', that is its heritage, due to these forces. The carefully manipulated heritage of such brands today creates a clear and comprehensible chain of meaning for consumers to grasp. Country images and (micro) regional images, and accordingly their origin labelling, are seen as important to consumers and as a site where meaning can be adequately negotiated. Despite this, consumers however also deeply mistrust such labels in this contemporary hybrid and fragmented climate, especially in a less tangible form, that is at the supra-national level. 
The idea of the European Commission to introduce the supra-national origin marking scheme 'made in the EU' resulted in an upheaval of concerns by the industries. Thus, the purpose of this study was to explore the actual meanings attributed to such an umbrella label by various situated consumers and the perceptions of its viability. That is, to determine the working meanings attributed to a supra-national origin marking scheme by consumers themselves. A study was conducted using focus groups of consumers from various geographic regions, constituting in and out groups, to derive such working meanings. The study showed that there are no concrete meanings currently attributed to the EU construct (and consequently the EU marking scheme), as the Commission would have hoped. This case of the EU proved to be an illustrative situational example, revealing the complexity of meanings that consumers attribute to an origin marking scheme, especially at the supra-national level.

\subsection{The meanings attributed to a supra-national origin label}

The findings indicate, that the meanings which consumers attribute to supra-national labels appear to be governed primarily by two factors, the strength of the concept ('the infancy' in this case), which is dependant on the heritage of the concept. These factors were found to be prerequisites before a supra-nation can communicate information to consumers and be actively imagined in a holistic sense, as a single and comprehensible image. At the supra-national level, these initial requirements in the meaning chain to develop a consumer accepted origin concept, were found to be particularly weak and diverse. Without heritage and a clear conceptual meaning, consumers find it difficult to accept a place as an origin and attribute meaning to it. The implication of this is that as long as the EU is not conceived by consumers as having one unified image, with a reliable and consistent heritage, it can not be conceived as a place where products can come from, an origin. This renders insufficient such a proposed labelling scheme at the supra-national level. This indicates that the EU's proposition to introduce a 'made in the EU' label will not be currently accepted by consumers, due to these mentioned deficiencies in the consumers' negotiation of meaning. Consumers foreseeably may accept this label one day if it is able to communicate tangible meaning (and accordingly interact with the consumer meaning systems) by 'manufacturing' the requirements as mentioned above- heritage and strong social concept. The research indicated that the Commission does not recognize these prerequisites and assumes that a supra-nation comes equipped with heritage or can borrow it from Europe or even member states, and hence arrogantly does not see that an origin does not just 'come with the label'. Whilst a nation's image is bound up with the social concept of the nation (O'Shaughnessy and O'Shaughnessy, 2000), and the EU apparently lacks this social concept, it has to find a new way of manufacturing an identifiable image.

In addition to this, this study indicated that an origin marking scheme in any sense does not have the ability to make a supra-national origin appear homogenous and communicate coherent meanings to consumers. This is reflected in the contemporary shift as our findings indicate that consumers draw origin information predominantly from other more 'trusted' information sources such as brands. 


\subsection{Contributions and relevance of the findings for the origin literature}

\section{Supra-national origins need their own literature}

The majority of the existing body of work in the origin field has been based on country of origin effects. This research has proved to be insightful and viable as consumers have proved to perceive origins at the country level as more solid entities, in which less diverse meanings (in an 'abstract sense') are attached to, thus these constructions are able to be conceived by consumers with greater ease. The majority of theory in this field, origin as conceived at the country-level, and its premises have also been applied to the regional level (predominantly at the micro-regional level). This study supports the existing literature, that when the concept of origin is stretched (or shrunk to a more obscure concept), it becomes more 'blurred' and reliant on 'heritage'. When this concept of origin is stretched even further to a supra-national level (where variance has increased immensely), this study found that the result was greater confusion, as there is less meaning and heritage, in which consumers can use as a tool to evaluate meaning with. This confusion was apparent, as mentioned, through consumer's perception of variance in the region, lack of knowledge and the infancy of the supra-national construct. Thus, the implication is not only that supra-national stretched origins need to develop their own research tradition, but the literature at the country level should be attuned in light of certain revelations of this research. That is, that the origin cue is strongly reliant on heritage and publicly recognised social concepts, which need to be explicitly recognised at all research 'levels' of the origin cue (micro-region, country, macroregion, supra-national region).

\section{Brands' 'perceived origin' as the new origin cue}

The findings indicated that the declining acceptance and trust of origin labels is not occurring at the supra-national level, as investigation examines, but in a more general sense, as globalization has weakened the strengths of such 'origin constructs' already established. The findings indicated that this is amplified by the processes of globalization, necessitating a shift within the origin's imagining.

Thus, today it is likely that consumers rather use the perceived 'country of brand origin' to provide the information that was traditionally drawn from the 'country of origin', quite simply because information about origin has become confusing to them, especially when consumers are asked to negotiate difficult, stretched and 'infant' constructs such as the 'EU' and 'made in the EU'. The growth of multinational companies and the increase of hybrid products are the basis for this shift, it is now reasonable to believe that consumers will increasingly extract information about brand origin. The country of brand origin possibly provides the next wave of comprehending how consumers perceive and evaluate products 'origins', which has certain implications for the marketing and labelling of such products. Arguably, 'origins' must become more like brands in the consumer psyche. Consumers are now looking at brands to attain origin information, as opposed to traditional cues such as the origin label. This shift is arguably a product of the increasing manipulation of brands, by brand manager's, marketers and strategists.

\subsection{Concluding comments}

Thus, the implication and contribution of this situational study is not that the literature on the origin cue is no longer relevant at the supra-national level, but that at this level, consumers attribute meaning differently and less easily. Arguably, consumers want to be informed by systems of meanings that they are comfortable with, which currently renders such supra-national origin marking scheme proposals unviable to them. 


\section{$7 \quad$ LIMITATIONS}

This study is reflexive about some of its inherent limitations, which should be considered. The emphasis of this study was on reaching understanding and attaining an assortment of meanings rather than generalization. As the exploration in this area, the EU as an origin construct, is in a very early stage, a small, yet in-depth empirical study was considered to be the best means by which to draw out meaning concerning the main themes. Because this study is a pilot study, it has not built upon any other knowledge concerning this specific construct, but on other constructs indirectly related to this research. Future research could potentially build upon the rich but inherently limited and 'infant' findings of this research.

Potential issues arising from the researchers' choice of methodology, convenience sample of international students, and data collection through the focus group method, were already addressed earlier in this report. It is acknowledged that more experiences and findings could have been forthcoming if a greater amount of participants with a wider diversity had been consciously sought. Most of the participants were acquaintances of the researchers, and did also know each other; however this seemed to encourage conversation more than hinder it. Another key limitation of this study is that respondents were not motivated by real purchase situations, however, if a 'real environment' setting was used, it would have been very difficult to control the availability of other external informational cues, which the respondents may process in such real life situations. Another limitation to this study is the use of a single cue approach, that is presenting COO information as the only piece of product information. Even though most COO studies have used a single-cue approach, it is criticisable. Single cue studies enhance the artificiality of the study due to the absence of other intrinsic or extrinsic cues, and might therefore over-estimate the impact of COO. Another issue which compromises a real life situation is the use of a sole origin mark 'made in the EU'. This might additionally dilute the meaning which is put on the EU label, since participants were not sure about what to compare it to, for example home-grown products or 'made in China' labels. It is further acknowledged that the comments of the participants could have been influenced by their aspiration to appear more cosmopolitan and impress both the researchers and other group members with their comprehension of Europe and the EU.

The findings in this research comprise region and time specific assumptions that are not easily transferable to different contexts. The contextual grounding of such research renders even different contextual investigations of similar subject matter inapplicable. Because of the emergence of new, and the expansion of existing, trade blocs, the findings of this study can be generalized limitedly, and future research in a different time and place context is also considered valuable. 


\section{COMMERCIAL IMPLICATIONS}

\section{The EU as a brand}

The act of putting a mark on a product, such as a 'made in' origin scheme can be seen as an act of branding (Kapferer, 2004). Yet such an origin marking scheme is not always intended to act as a 'branding' function. Such a mark does not always operate as a brand or is perceived as a brand by consumers. For a brand to function this way, it typically has to be built up and designed this way. According to Kapferer (2004, p.10), a brand is a "set of mental associations held by the consumer, which add to the perceived value of a product or service", and according to the American Marketing Association (AMA), a brand is a 'name, term, sign, symbol, or design, or a combination of them, intended to identify the goods and services of one seller or group of sellers and to differentiate them from those of competition' (Kotler, 2003). These definitions imply that the benefits have to be realised by the consumer. Thus, whilst the effects of an origin mark should act like a brand or a mark of ownership they are not being perceived this way by consumers. Branding no longer is just about putting a mark on the product; it is about the manufacturing of equity for the consumer through a strong heritage and social concept.

\section{Trade blocs as an un-chartered brand territory}

The EU must be reflective of the fact that its 'produce' represents and encompasses a variety of factors and associations, such as place, natural resources and local products, people, history, culture, language, political and economic systems and social institutions, that go beyond the scope of the traditional concept of product or nation branding (Fan, 2005). Whilst this extra variable and factors to control in the consumer psyche, will pose a challenge, arguably the best way under these circumstances, is to treat such a concept like a corporate multi-national brand. Whilst the nation branding literature may prove to be prosperous, the fact is that the EU in its variance resembles a multi national company with a diverse product portfolio, more than a national brand, and hence should be branded to build a strong heritage and social concept. No research has been done to date regarding the branding of 'trade blocs'. This research's implication however is, that they should be branded to facilitate them to be perceived as an origin by consumers.

\section{The construction of a 'made in the EU' label must be treated like the launch of a corporate brand}

Hence the EU can be conceived like a company's corporate identity, it has certain 'founding' values and ethics. It also has an organisational focus and culture, like any multi-national company (Kapferer, 2004). This has to translate values, which can be comprehended to the brand identity 'made in the EU'. Without these values there can be no linkage or successful transfer, between the EU and the, 'made in the EU' (Kapferer, 2004).

These values are what communicates the equity of the made in the EU label and sets up a chain of meaning for consumers to comprehend. Reflective of these values is the 'brand identity,' that is the 'made in label,' this must have a physique, a personality, a relationship to the consumer, a culture associated with it, be able to reflect a consumers identity and have a strong 'self-concept' (Kapferer, 2004). Branding this way will set up a manageable system of symbolic meanings for consumers and a viable and more 'commonly' defined construction for consumers. 


\section{Umbrella branding}

Once the 'made in' master brand is set up, the EU would hypothetically operate like an 'umbrella brand' (see figure 3). This relates back to the British branding guru Simon Anholt's ${ }^{8}$ idea of branding the EU to operate like al-Qaeda with many separate 'terrorist cells'- that is, having an organisational head that oversees many discrete interrelated, but independent parts (Bounds, 2006). Arguably, Anholt is referring to the logic of an umbrella brand, this would allow the EU some practical 'flexibility' and the ability to grow and extend; he refers to this ideas in a purely hypothetical sense.

The 'umbrella branding' 'brand architecture' is used when the same corporate brand name is visible and supports several products in different markets (Kapferer, 2004). This architecture allows the 'brand' itself to not be typically associated with any specific products or markets, and to freely extend based on the master brands 'abstract values'. It would allow the 'made in the EU' to cross product and market boundaries more easily than other 'made in' label. The benefit of using this strategy is the ability to capitalise on one single name and create economies of scale on an international level. It allows the brand or in this case 'origin' to become more tangible and meaningful to consumers and be nurtured by association with products that it was not previously associated with. Another important issue is that the umbrella brand strategy has few limitations and communicates a clear set of values. The disadvantage of the umbrella branding strategy is the effect it can cause if a crisis was to occur to one of the products or services, in this case regions, it could lead to tremendous problems to other products under the same umbrella (Kapferer, 2004). This is where the importance of enforced values and standards comes in of the EU.

\section{Figure 3}

An EU umbrella brand

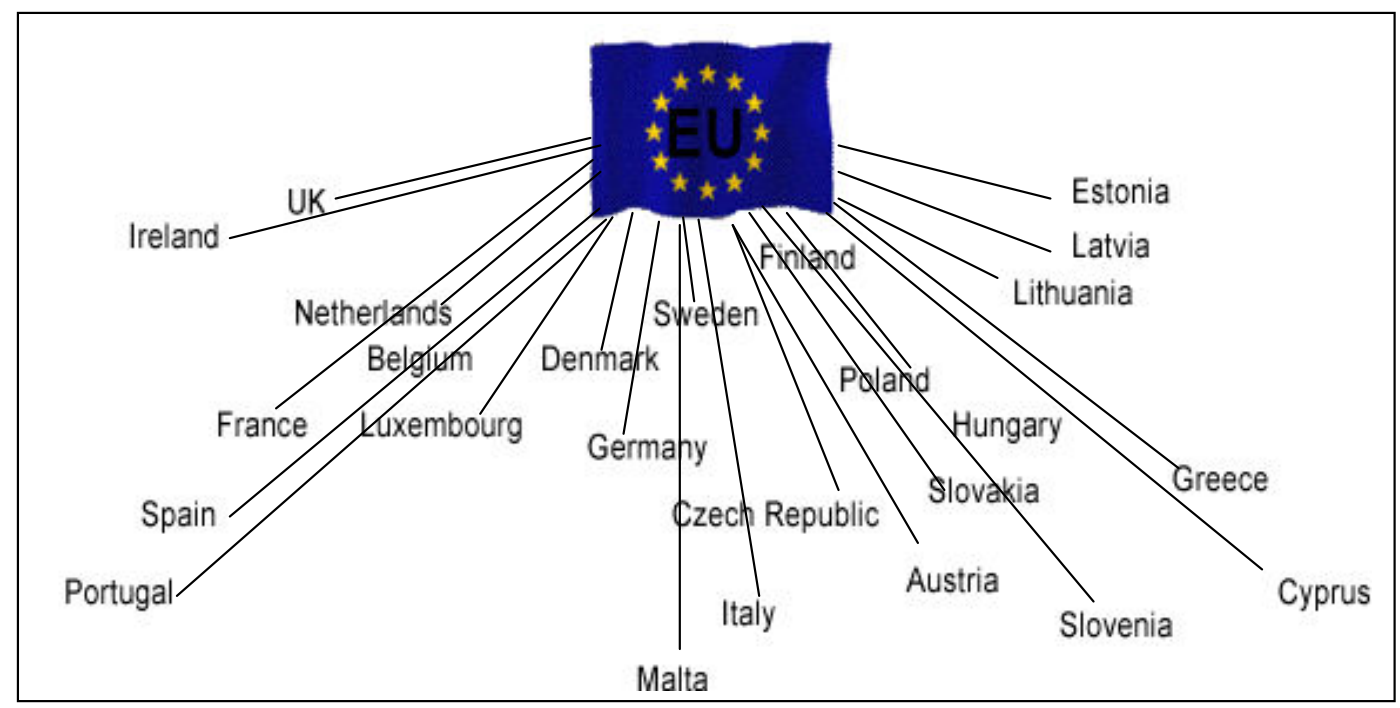

Figure 3 - The architecture of a hypothetical EU umbrella brand, with countries functioning as brand extensions.

\footnotetext{
${ }^{8}$ According to the Financial Times on May 1, 2006 Simon Anholt, a British brand consultant, was hired to chair a panel of branding experts on European Identity (Bounds, 2006). On May 2, 2006, according to the EU observer, the European Commission's chief spokesperson denied reports that it has consulted Simon Anholt to re-brand the EU (Spongenberg, 2006)
} 
Umbrella branding is an illustrative example of how a corporate brand or 'origin', such as 'made in the EU', can be stretched. Like brand extensions into the distant product categories, the EU can also capitalise on these extensions, into various product categories, that it may not be associated or 'stereotyped' with traditionally. This is facilitated by the fact that the master brand (which is branded on the diverse 'product extensions', is based on certain abstract values), this also allows variance in products, which accommodates the various countries, differences and capabilities, if it is united under a common set of values that are the umbrella brand. That is the EU would be able to launch various dissimilar product categories (with its made in label), through stressing the intangible benefits of its 'value-based' corporate brand. This would have to be heavily enforced and monitored. That is the EU's extensions and products all relate back to the strength of its 'kernel' (its core values).

\section{The communication of heritage and the creation of a social concept}

Whilst the above suggestions are feasible guidelines for the launch of a traditional brand or a 'manufactured' origin, it is no easy task to create a brands heritage, this takes time and is reliant on the repeated successful associations which are consistent in communicating the brand's value, as the brand develops, its social concept strengthens, as does its heritage. Brands such as Barilla and Sony were not born over night but the heritage developed with time. The 'made in the EU' origin scheme will have to be reflective of this before it can start thinking about the benefits of umbrella branding and other broad brands. The EU must initially set the chain of meanings in motion, at the consumer level before it even consider s launching such a label. 


\section{REFERENCES}

Anderson, Benedict (1991), "Imagined Communities: Reflections on the Origin and Spread of Nationalism", revised edition, London and New York, Verso

Bounds, Andrew (2006), "Brand experts study EU identity crisis", Financial Times Online, , Available at [http://www.nationbrandindex.com/docs/FT_5106.pdf], Accessed on May 9, 2006

Bryman, Alan and Bell, Anna (2003), "Business Research Methods", New York, Oxford University Press Inc

Cox, R.C. and West W.L. (1986), "Fundamentals of research for health professionals", 2nd ed. Ramsco Publishing Co.

Darling, J.R and Kraft, F.B (1977) "A competitive profile of products and associated marketing practices," European Journal of Marketing, Vol.11 No.7, pp.11-23

Dimitrius S. and Aleka V.(2002), "Consumers' willingness to pay for origin labelled wine: A Greek case study,” British Food Journal, Vol.104 No.10-11, pp. 898-912

Dornoff, R. et al. (1974) "Consumers' perceptions of imports," $\underline{\text { Akron Business and Economic }}$ Review, Vol. 5, Summer, pp.26-29

Easterby-Smith, Mark, Thorpe, Richard, Lowe, Andy (2003), "Management Research - An Introduction" 2nd ed, London, Sage Publications Ltd

Fan, Ying (2005), "Branding the nation: What is being branded", Journal of Vacation Marketing, 2006, Vol.12, Iss.1, pp.5-14

Geertz, C. (1973), “Thick Description”, in The Interpretation of Cultures, New York: Basic Books, pp.3-30

Ger G. et al. (1999) "Experiential Nature of Product- Place Images: Image as a Narrative," Advances in Consumer Research, Vol.26, pp. 165-169

Greer, T.V. (1971) "British purchasing agents and European Economic Community: some empirical evidence on international industrial perceptions," Journal of Purchasing, Vol.7, pp.56-63

Han, C.M. (1989) "Country image: halo or summary construct?", Journal of Marketing Research, Vol.26, May, pp.222-229

Han, C.M.(1990) "Testing the role of country image in consumer choice behaviour", European Journal of Marketing, Vol. 24 No.6, pp. 24-39

Hitchins, Keith (2001), “The Idea of Nation among the Romanians of Transylvania, 1700-1849”, International Symposium held at the New Europe College, Bucharest, April 6-7, 2001

Hudson, L.A and Ozane, J. (1988), "Alternative Ways of Seeking Knowledge in Consumer Research", Journal of Consumer Research, Vol. 14 No.4, pp.508-521 
Illbery, B. and Kneafsey, M. (2000) "Producer constructions of quality in regional specialty food production: a case study from south west England", Journal of Rural Studies, Vol.16 No. 2 pp.217-230

Ittersum, K. et al. (2003) "The influence of the image of a product's region of origin on product evaluation", Journal of Business Research, Vol. 56, No. 3, pp. 215-226

Kapferer, Jean-Noel (2004), "The New Strategic Brand Management- Creating and Sustaining Brand Equity Long Term”, Kogan Page. London and Sterling, VA

Kaufmann, O. (1972), "Strategies of Expansion and Organizational Developments in European and American Firms", Journal of Management Studies, Feb 1972, pp.82-96

Klein, H. K. and Myers, M. D. (1999), "A Set of Principles for Conducting and Evaluating Interpretive Field Studies in Information Systems", MIS Quarterly, 23 (1), 67-94.

Kotler, Philip (2003), "Marketing Management", $11^{\text {th }}$ ed., Prentice Hall

Lincoln, Y.S., and Guba, E. (1985), "Naturalistic Inquiry", Beverly Hills, California, Sage Publications, Inc.

Littler, Dale and Schlieper, Katrin, "The Development of Eurobrands", International Marketing Review, 1995, Vol. 12, No.2, 22-37

Lunsford TK. (1995), "The Research Sample, Part I: Sampling”, Journal of Prosthetics and Orthotics, Volume 7, Number 3, pp. 105-112.

Mamadouh, Virginie (1998), "Supranationalism in the European Union: what about multilingualism?", World Political Map Conference on Nationalisms and Identities in a Globalized World, Maynooth/Belfast, 17th-23rd August 1998

Nagashima, A. (1970) "A comparison of Japanese and U.S attitudes toward foreign products", Journal of Marketing, Vol. 34, pp.68-74

Ofir, C. and Lehmann, D. (1986) "Measuring images of foreign products", Columbia Journal of world Business, Summer, pp.105-8

O'Shaughnessy John, and O'Shaughnessy, Nicholas Jackson (2000), "Treating the Nation as a Brand: Some Neglected Issues", Journal of Macromarketing, June 2000, Vol.20, Iss.1, pp.5664

Ozsomer, A. and Cavusgil, S. (1991) "Country-of-origin effects on product evaluations: a sequel to Bilkey and Nes Review", in Gillyet al.(Eds), AMA Educators Proceedings, Vol.2, Chicago, pp.269-77.

Papadopoulos, Nicolas (1992), "Trade Blocs and Marketing: Antecedents, Trends, and Implications", Journal of Global Marketing, 1992, Vol.5, Iss.3, pp.1-29

(1993), "What country images are and are not", in Papadopoulos, N. and Heslop, L. (Eds), Product Country Images, International Business Press, New York. 
and Heslop L. (2002), "Who controls the purse strings. A study of consumer's and retail buyers' reactions in America's FTA environment", Journal of Business Research, Vol. 57, pp $1177-1188$

Reirson, C. (1967), "Attitude changes toward foreign products," Journal of Marketing Research, Vol.4, November, pp.385-87

Ritson, M. (2003), "Parma ham maintains heritage as EU strikes blow for branding," Marketing, pp.16

Rosamond, B. (2002), "Imagining the European Economy: 'Competitiveness' and the Social Construction of 'Europe' as an Economic Space," New Political Economy, Vol. 7, No.2, pp. 157-177

Rugimbana R.et al.(2000), "The impact of "Consumer Cringe” on Developing Regional Trade Blocs: A Tanzanian Case Study”, Journal of African Business Vol. 1 No.2, pp.91-106

Samiee, S. (1994), "Customer evaluation of products in a global market", Journal of International Business Studies, Vol. 25 No.3, pp.579-604

Schooler, R.D. (1965), "Product bias in the central American common", Journal of Marketing Research, November, pp.394-7

(1971), "Bias phenomena attendant t market to the marketing of foreign goods in the US", Journal of International Business Studies, Vol.2 No.1, pp.71-81

Schweiger, G. et al. (1995), "Consumers' evaluations of products labelled 'made in Europe", Marketing and Research Today, February 1995, Vol.23, Iss.1, pp.25-34

Smith, W.R (1993), "Country-of-origin bias: a regional labelling solution", International Marketing Review, Vol.10 No.6, pp.4-12

Smith, Anthony D, 1995, "Nations and Nationalism in a Global Era". Cambridge: Polity.

Spongenberg, Helena (2006), "Europe - Commission denies EU branding", Available at [http://www.ezilon.com/information/article_16608.shtml], Accessed on May 9, 2006, 


\section{APPENDIX}

Appendix 1 - A hypothetical image of the EU's proposed supra-national made in label

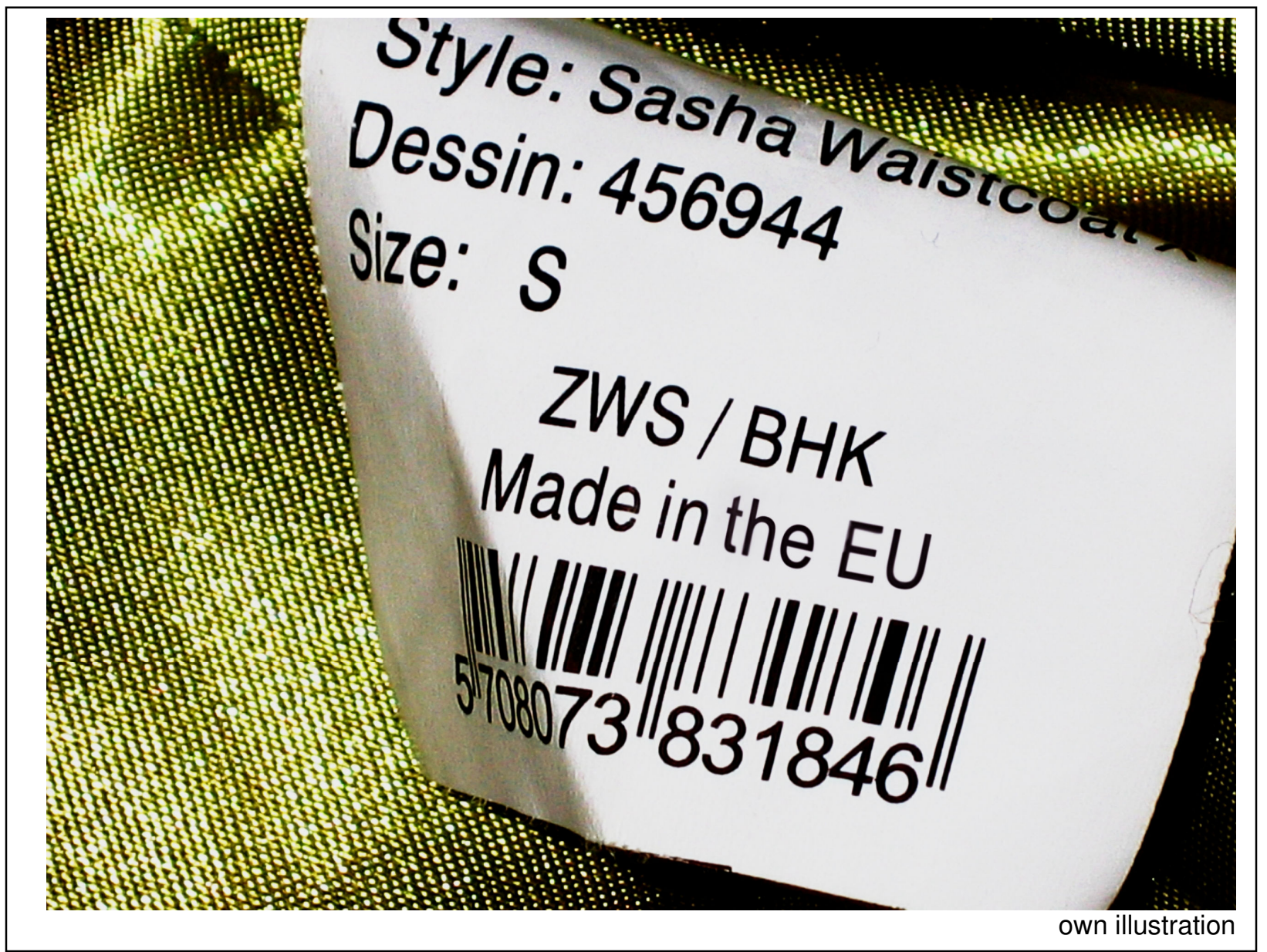

Appendix 2 - Image of the results from a focus group's exercise.

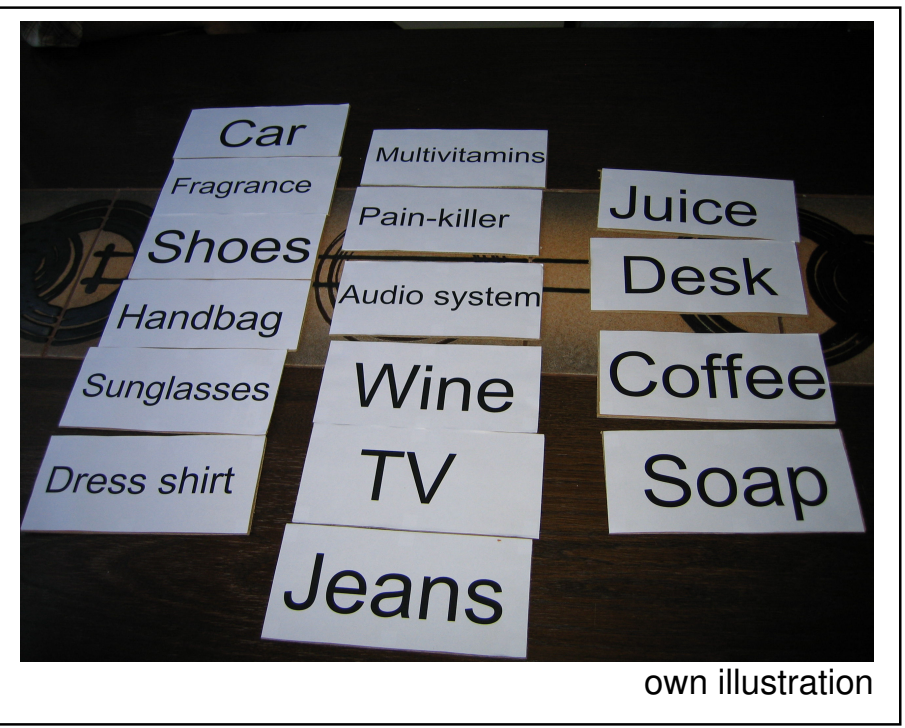

